\title{
Impaired Constitutive and Regenerative Neurogenesis in Adult Hyperglycemic Zebrafish
}

\author{
Anne-Claire Dorsemans, ${ }^{1,2}$ Stéphanie Soule, ${ }^{1,2}$ Meltem Weger, ${ }^{3}$ Emmanuel Bourdon, ${ }^{1,2}$ \\ Christian Lefebvre d'Hellencourt, ${ }^{1,2}$ Olivier Meilhac, ${ }^{1,2,4}$ and Nicolas Diotel ${ }^{1,2}$ * \\ ${ }^{1}$ Inserm, UMR 1188 Diabète athérothrombose Thérapies Réunion Océan Indien (DéTROI), plateforme CYROI, Sainte-Clotilde \\ F-97490, France \\ ${ }^{2}$ Université de La Réunion, UMR 1188, Sainte-Clotilde, F-97490, France \\ ${ }^{3}$ Institute of Cancer and Genomic Sciences, College of Medical and Dental Sciences, University of Birmingham, Birmingham \\ B15 2TT, UK \\ ${ }^{4} \mathrm{CHU}$ de La Réunion, F-97400 Saint-Denis, France
}

\begin{abstract}
A growing body of evidence supports hyperglycemia as a putative contributor to several brain dysfunctions observed in diabetes patients, such as impaired memory capacity, neural plasticity, and neurogenic processes. Thanks to the persistence of radial glial cells acting as neural stem cells, the brain of the adult zebrafish constitutes a relevant model to investigate constitutive and injury-induced neurogenesis in adult vertebrates. However, there is limited understanding of the impact of hyperglycemia on brain dysfunction in the zebrafish model. This work aimed at exploring the impact of acute and chronic hyperglycemia on brain homeostasis and neurogenesis. Acute hyperglycemia was shown to promote gene expression of proinflammatory cytokines (il1 $\beta$, ill, il/, and thf $\alpha$ ) in the brain and chronic hyperglycemia to impair expression of genes involved in the establishment of the blood-
\end{abstract}

brain barrier (claudin 5a, zona occludens 1a and b). Chronic hyperglycemia also decreased brain cell proliferation in most neurogenic niches throughout the forebrain and the midbrain. By using a stab wound telencephalic injury model, the impact of hyperglycemia on brain repair mechanisms was investigated. Whereas the initial step of parenchymal cell proliferation was not affected by acute hyperglycemia, later proliferation of neural progenitors was significantly decreased by chronic hyperglycemia in the injured brain of fish. Taken together, these data offer new evidence highlighting the evolutionary conserved adverse effects of hyperglycemia on neurogenesis and brain healing in zebrafish. In addition, our study reinforces the utility of zebrafish as a robust model for studying the effects of metabolic disorders on the central nervous system. J. Comp. Neurol. 000:000-000, 2016.
Hyperglycemia corresponds to abnormally high blood glucose levels, which may reflect a response to situations of acute stress or to a chronic disorder of insulin secretion and/or resistance (diabetes). The prevalence of type 2 diabetes (characterized by insulin resistance) has increased rapidly in recent decades in association with drastic changes in lifestyle (Lee et al., 2012; World Health Organisation, 2015a,b). Today, 382 million people suffer from type 2 diabetes, and 14,000 people die daily from this disease or its related complications. Thus, type 2 diabetes is a major health problem and is projected to affect 592 million people by 2035 (IDF, 2015).

Hyperglycemia is a complex and multifactorial state caused by both genetic and nongenetic factors. It is associated with an increased risk of mortality related to cerebrovascular and renal dysfunctions, cancers, sepsis, and also neuropathies (Koh et al., 2012; Storey and

Grant sponsor: La Réunion University (Bonus Qualité Recherche, Dispositifs incitatifs); Grant sponsor: Conseil Régional de La Réunion, European Union (CPER/FEDER); Grant sponsor: Philancia Association; Grant sponsor: Ministère de l'Education Nationale, de l'Enseignement Supérieur et de la Recherche, La Réunion University (Contrat Doctoral) (fellowship grant to A.C.D.).

${ }^{*}$ CORRESPONDENCE TO: Dr. Nicolas Diotel, Inserm U1188, Université de La Réunion, Equipe DéTROI, Plateforme CYROI, 2 rue Maxime Rivière, 97490 Sainte-Clotilde, France. E-mail: nicolas.diotel@univ-reunion.fr 
Von Ah, 2012; Hafez et al., 2014; Lee et al., 2015). Furthermore, hyperglycemia is an independent risk factor for ischemic stroke and is a predictor of adverse neurological and survival outcomes (Kagansky et al., 2001; Gilmore and Stead, 2006; Desilles et al., 2013). Hyperglycemia has been shown to sensitize the brain against endogenous aggressions (Sander and Kearney, 2009). Both acute and chronic hyperglycemia increase oxidative stress and stimulate the production of proinflammatory cytokines that display deleterious effects on different organs (e.g., eyes, kidney, heart, brain) and that alter various physiological processes (Kodl and Seaquist, 2008; Kayama et al., 2015; Tangvarasittichai, 2015). In the central nervous system, chronic and acute hyperglycemia disrupt energy homeostasis, neural activity, and neural functions, which may alter cognition and promote dementia and depression (Dejgaard et al., 1991; Cukierman et al., 2005; Brismar et al., 2007; Gaudieri et al., 2008; Lang et al., 2009; Lu et al., 2009; Ho et al., 2013; Ojo and Brooke, 2015). In addition, diabetes may impact adult neurogenesis (Ho et al., 2013), a physiological process leading to the generation of functional neurons from neural stem/progenitor cell proliferation.

In mammals, adult neurogenesis occurs throughout life in two main neurogenic regions: the dentate gyrus of the hippocampus and the subventricular zone of the lateral ventricle (Lindsey and Tropepe, 2006; Grandel and Brand, 2013). Additional neurogenic niches have also been described such as in the hypothalamus (Migaud et al., 2010; Batailler et al., 2014). Adult neurogenesis is regulated by intrinsic and extrinsic factors (Hsieh, 2012) and is markedly blunted under pathological conditions such as epilepsy and stroke (particularly in cases involving increased blood-brain barrier [BBB] permeability), in the contexts of increased oxidative stress and of inflammation (Zhao et al., 2008; Lin et al., 2015). Unlike mammals, adult teleost fish exhibit intense and widespread neurogenic activity throughout life and maintain a greater capacity for central nervous system repair after injury (Kizil et al., 2012; Schmidt et al., 2013). In teleosts, such capacities are notably due to the persistence of radial glial cells acting as neural progenitors, as well as to further committed progenitors corresponding to neuroblasts (Chapouton et al., 2007; März et al., 2010; Lindsey et al., 2012). In the zebrafish telencephalon, the ventricular zone is described as comprising quiescent radial glial cells (type 1 progenitors), actively divided radial glial cells (type 2 progenitors), and neuroblasts (type 3 progenitors), mainly clustered in the subpallium (März et al.,

\begin{tabular}{|c|c|c|c|}
\hline \multirow[b]{2}{*}{$A$} & \multicolumn{3}{|c|}{$\begin{array}{l}\text { Abbreviations } \\
\text { Anatomical terms used in this study are according to the Wullimann atlas (Wullimann et al., 1996) }\end{array}$} \\
\hline & anterior thalamic nucleus & NIII & oculomotor nucleus \\
\hline APN & accessory pretectal nucleus & NMLF & nucleus of medial longitudinal fascicle \\
\hline ATN & anterior tuberal nucleus & NLV & nucleus lateralis valvulae \\
\hline BBB & blood-brain barrier & PG & preglomerular nucleus \\
\hline $\mathrm{CCe}$ & corpus cerebelli & PGa & anterior preglomerular nucleus \\
\hline Chab & habenular commissure & PGI & lateral preglomerular nucleus \\
\hline Chor & horizontal commissure & p.i. & post-injection \\
\hline $\mathrm{CM}$ & corpus mamillare & Pit & pituitary \\
\hline $\mathrm{CP}$ & central posterior thalamic nucleus & $\mathrm{PO}$ & posterior pretectal nucleus \\
\hline CPN & central pretectal nucleus & $\mathrm{PPa}$ & parvocellular preoptic nucleus, anterior part \\
\hline Cpop & postoptic commissure & $\mathrm{PPp}$ & parvocellular preoptic nucleus, posterior part \\
\hline Cpost & posterior commissure & PR & posterior recess of diencephalic ventricle \\
\hline $\mathrm{D}$ & dorsal telencephalic area & PSp & parvocellular superficial pretectal nucleus \\
\hline Dc & central zone of dorsal telencephalic area & PTN & posterior tuberal nucleus \\
\hline Dd & dorsal zone of dorsal telencephalic area & $\mathrm{PPv}$ & periventricular pretectal nucleus \\
\hline DI & lateral zone of dorsal telencephalic area & $\mathrm{R}$ & rostrolateral nucleus \\
\hline $\mathrm{Dm}$ & medial zone of dorsal telencephalic area & RF & reticular formation \\
\hline DOT & dorsomedial optic tract & RV & rhombencephalic ventricle \\
\hline $\mathrm{Dp}$ & posterior zone of dorsal telencephalic area & SC & suprachiasmatic nucleus \\
\hline DP & dorsal posterior thalamic nucleus & so & secondary octaval population \\
\hline DTN & dorsal tegmental nucleus & $\mathrm{TeO}$ & tectum opticum \\
\hline $\mathrm{ECL}$ & external cellular layer of olfactory bulb & $\mathrm{TL}$ & torus longitudinalis \\
\hline EG & eminentia granularis & TLa & torus lateralis \\
\hline ENv & entopendoncular nucleus, ventral part & TPp & periventricular nucleus of posterior tuberculum \\
\hline FR & fasciculus retroflexus & TS & torus semicircularis \\
\hline $\mathrm{GL}$ & glomerular layer of olfactory bulb & V & ventral telencephalic area \\
\hline $\mathrm{Had}$ & dorsal habenular nucleus & V3 & third ventricle \\
\hline Hav & ventral habenular nucleus & VII & sensory root of the facial nerve \\
\hline $\mathrm{Hc}$ & caudal zone of periventricular hypothalamus & VIII & octaval nerve \\
\hline $\mathrm{Hd}$ & dorsal zone of periventricular hypothalamus & $\mathrm{VCe}$ & valvula cerebelli \\
\hline HG & hyperglycemia & $\mathrm{Vd}$ & dorsal nucleus of ventral telencephalic area \\
\hline $\mathrm{Hv}$ & ventral zone of periventricular hypothalamus & $\mathrm{VL}$ & ventrolateral thalamic nucleus \\
\hline $\mathrm{ICL}$ & internal cellular layer of olfactory bulb & VM & ventromedial thalamic nucleus \\
\hline IL & inferior lobe & VOT & ventrolateral optic tract \\
\hline i.p. & intraperitoneal injection & $V p$ & post-commissural nucleus of ventral telencephalic area \\
\hline $\mathrm{LH}$ & lateral hypothalamic nucleus & Vv & ventral nucleus of dorsal telencephalic area \\
\hline LLF & lateral longitudinal fascicle & ZL & zona limitans \\
\hline LR & lateral recess of diencephalic nucleus & & \\
\hline
\end{tabular}


2010). The zebrafish has recently emerged as a relevant and useful model for studying hyperglycemia and type 2 diabetes (Sarras and Intine, 2013; Capiotti et al., 2014a; Connaughton et al., 2016), which may be useful for analyzing the impact of both acute and chronic hyperglycemia on brain plasticity and neurogenic processes.

In the current study, we set up an acute model of hyperglycemia and investigated the effects of both acute and chronic hyperglycemia on brain cell proliferation under homeostatic and regenerative conditions in zebrafish. We show that hyperglycemia upregulates the expression of proinflammatory cytokines in the brain, disturbs the expression of genes involved in the establishment of the BBB, and impairs both constitutive and regenerative neurogenesis.

\section{MATERIALS AND METHODS}

\section{Animals and ethics}

Adult male and female wildtype zebrafish (Danio rerio) of 3-6 months in age were purchased from commercial suppliers and maintained under standard conditions of photoperiod (14/10 hours light/dark) and temperature $\left(28 \pm 1^{\circ} \mathrm{C}\right)$. The zebrafish were fed daily with commercially available dry food (TetraMin, Germany). Animals were euthanized by rapid chilling on ice to induce a lethal shock before spinal cord sectioning. For all "surgery" procedures and/or injections, fish were deeply anesthetized with $0.02 \%$ tricaine (MS-222; REF: A5040, Sigma-Aldrich, Germany). All experiments were conducted in accordance with the French and European Community Guidelines for the Use of Animals in Research (86/609/EEC and 2010/63/EU) and approved by the local Ethics Committee for animal experimentation (APAFIS\#2645-2015111308416542; APAFIS\#3625-2016011516473942; APAFIS\#2646$2015111315373106)$.

\section{Hyperglycemia models}

To assess the impact of hyperglycemia in zebrafish, animals were submitted to acute or chronic exposure to D-glucose (Sigma-Aldrich). Acute hyperglycemia $(A H G)$ was induced by an intraperitoneal (i.p.) injection of D-glucose $(2.5 \mathrm{~g} / \mathrm{kg}$ of body weight) dissolved in a $50 \mu \mathrm{L}$ saline phosphate buffer (PBS; pH 7.4). The respective control fish were injected with $50 \mu \mathrm{L}$ of PBS. Chronic hyperglycemia (CHG) was induced by fish water supplementation with $111 \mathrm{mM}$ D-glucose over a period of 14 days, as previously described by Capiotti et al. (2014a). Fish water was changed every 2 days.
For acute HG and chronic HG models, control fish were rigorously maintained in the same conditions (light, temperature, and environment) as treated fish.

\section{Measurement of blood glucose levels}

Determination of blood glucose levels was performed after a 12-hour fasting period. Fish were euthanized at the same time of day and gently washed and dried prior to blood glucose level measurement. One eye was removed, and a glucometer test strip (One-Touch Ultra, LifeScan, France) was directly inserted in the ocular cavity. Fish were considered hyperglycemic when glycemia was found to be higher than $100 \mathrm{mg} / \mathrm{dl}$. Fish following hyperglycemic treatment and displaying blood glucose levels $<100 \mathrm{mg} / \mathrm{dl}$ were excluded from the study.

\section{Stab wound of adult zebrafish telencephalon}

Prior to stab wounding, zebrafish were deeply anesthetized with $0.02 \%$ tricaine. Mechanical injury to the telencephalon was performed by inserting a sterile nee-

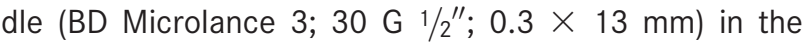
right telencephalic hemisphere, following a dorsoventral axis and guided by landmarks on the head, as previously described (Diotel et al., 2013). After the procedure fish were put back into their respective tanks and maintained until recovery.

\section{Tissue preparation}

For paraffin immunohistochemistry, fish were euthanized before being decapitated. Zebrafish heads were immersed overnight at $4^{\circ} \mathrm{C}$ in $4 \%$ paraformaldehyde (PFA) dissolved in PBS. The next day, brains were extracted from the skull and postfixed in 4\% PFA-PBS overnight at $4^{\circ} \mathrm{C}$ before paraffin embedding. For freefloating vibratome section immunohistochemistry, fixed brains were stepwise dehydrated in a methanol/PBS concentration series and stored at $-20^{\circ} \mathrm{C}$, as previously described (Adolf et al., 2006).

\section{Immunohistochemistry}

For paraffin immunohistochemistry, zebrafish brains were cut into 7- $\mu m$-thick coronal sections using a microtome (Microm HM 355 S, Thermo Scientific, Pittsburgh, PA), and double glial fibrillary acidic protein (GFAP)/proliferating cell nuclear antigen (PCNA) immunostainings were performed as follows. The sections were dewaxed in xylene, progressively rehydrated through graded ethanol (100 to $50 \%$ ), and then rinsed in PBS containing $0.2 \%$ Triton X-100 (PBS-T). Antigen retrieval was performed in a sodium citrate buffer $(\mathrm{pH}$ 6.0) in a microwave oven (750W, 2 minutes). After washing in PBS-T, the sections were saturated in PBS-T 
TABLE 1.

Primary and Secondary Antibodies

\begin{tabular}{|c|c|c|c|}
\hline \multicolumn{4}{|c|}{ Primary antibodies } \\
\hline Antibodies & Reference & RRID & Antigen \\
\hline $\begin{array}{l}\text { Polyclonal rabbit anti glial fibrillary } \\
\text { acidic protein }\end{array}$ & $\begin{array}{l}\text { Z033429 } \\
\text { (Dako) }\end{array}$ & AB_2314535 & $\begin{array}{l}\text { GFAP isolated from cow spinal } \\
\text { cord }\end{array}$ \\
\hline $\begin{array}{l}\text { Proliferating cell nuclear antigen } \\
\text { clone PC } 10\end{array}$ & $\begin{array}{l}\text { M0879 } \\
\text { (Dako) }\end{array}$ & AB_2160651 & $\begin{array}{l}\text { Rat PCNA-protein A fusion protein } \\
\text { obtained from vector pC2T } \\
\text { (Waseem and Lane, 1990) }\end{array}$ \\
\hline \multicolumn{4}{|c|}{ Secondary antibodies } \\
\hline Antibodies & & Reference & RRID \\
\hline Donkey anti-mouse Alexa Fluor 488 & & $\begin{array}{l}\text { A21202 } \\
\text { obes, Life Technologies) }\end{array}$ & $A B \_141607$ \\
\hline Donkey anti-rabbit Alexa Fluor 488 & & $\begin{array}{l}\text { A21206 } \\
\text { obes, Life Technologies) }\end{array}$ & $A B \_10049650$ \\
\hline Goat anti-mouse Alexa Fluor 594 & & $\begin{array}{l}\text { A11005 } \\
\text { obes, Life Technologies) }\end{array}$ & $A B \_141372$ \\
\hline
\end{tabular}

containing $0.5 \%$ milk powder to avoid nonspecific binding. The sections were then incubated overnight at room temperature with the following primary antibodies: polyclonal rabbit anti-GFAP (1:500; REF: Z033429, Dako, Carpinteria, CA; RRID: AB_2314535) and monoclonal mouse anti-PCNA (1:100; clone PC10, Dako; RRID: AB_2160651). The next day the sections were washed three times in PBS-T and incubated for 90 minutes at room temperature with $4^{\prime}, 6^{\prime}$-diamidino-2phenylindole (DAPI) for cell nuclei counterstaining and with the respective secondary antibodies: donkey antirabbit Alexa Fluor 488 (1:200; REF: A21206; Life Technologies, Bethesda, MD; RRID: AB_10049650) and goat anti-mouse Alexa Fluor 594 (1:200; REF: A11005; Life Technologies; RRID: AB_141372). Finally, the sections were washed three times in PBS-T and the slides were mounted with the antifading medium Vectashield $(\mathrm{H}-$ 1000, Vector Laboratories, Burlingame, CA).

For free-floating section immunohistochemistry using a vibratome, PCNA immunostaining was performed as follows. Zebrafish brains were progressively rehydrated through graded methanol (75 to $25 \%$ ) and rinsed in PBS. After washing in PBS containing $0.1 \%$ Tween-20 (PTW), the brains were embed in $2 \%$ agarose in PBS. Next, the brains were cut into $50-\mu \mathrm{m}$-thick free-floating sections on a vibratome (Vibratome Line VT1000S, Leica, Germany) in a blocking buffer (BB; PBS containing $0.1 \%$ Tween-10, $0.2 \%$ bovine serum albumin, $1 \%$ dimethyl sulfoxide). The sections were then incubated overnight at $4^{\circ} \mathrm{C}$ with the monoclonal mouse anti-PCNA (1:500; clone PC10, Dako) in BB. The next day, the sections were washed three times in PTW and incubated for 2 hours at room temperature with DAPI for cell nuclei counterstaining and with a donkey anti-mouse
Alexa Fluor 488 antibody (1:1000; REF: A21202; Life Technologies; RRID: AB_141607). Finally, the sections were washed three times in PTW and the slides were then mounted with the antifading medium Aqua Polymount (REF: 18606, Polysciences, Warrington, PA). No staining was observed after omission of the primary antibodies (data not shown). Table 1 summarizes the antibodies used in this study.

\section{Antibodies specificity}

PCNA and GFAP antibodies have been previously documented for their use and their specificity in zebrafish (Pellegrini et al., 2007; Lam et al., 2009; Diotel et al., 2010b, 2016; März et al., 2011; Baumgart et al., 2012).

Consistent with previous studies, PCNA-labeling was observed in cell nuclei across the neurogenic niches lining the ventricles as shown by Pellegrini et al. (2007). In addition, its distribution is similar to BrdU proliferative assay (Zupanc et al., 2005). GFAP-positive cells correspond to radial glial cell, as they display a soma localized along the ventricular layer and a long radial process that crosses the brain parenchyma and reaches the pial surface. Its expression and its distribution along the ventricles correspond to previous data obtained with the same antibody in zebrafish (Baumgart et al., 2012) or with GFAP:GFP transgenic line (Lam et al., 2009; März et al., 2010).

\section{Microscopy}

Sections were analyzed with an Eclipse 80i Nikon fluorescence microscope equipped with a Hamamatsu ORCA-ER digital camera (Life Sciences, Japan) or with a confocal microscope (Nikon D Eclipse C1), both of which 
TABLE 2.

qRT-PCR Primers

\begin{tabular}{|c|c|c|}
\hline Target & Forward primer & Reverse primer \\
\hline ef $1 \alpha$ & AGCAGCAGCTGAGGAGTGAT & CCGCATTTGTAGATCAGATGG \\
\hline il8 & GTCGCTGCATTGAAACAGAA & AGGGGTCCAGACAGATCTCC \\
\hline$i / \beta$ & GCTGGAGATCCAAACGGATA & ATACGCGGTGCTGATAAACC \\
\hline $\operatorname{tnf} \alpha$ & GCGCTTTTCTGAATCCTACG & TGCCCAGTCTGTCTCCTTCT \\
\hline il6 & TCAACTTCTCCAGCGTGATG & тстTтСССтстTтTССтсстG \\
\hline neurod4 & GGACAGGTGCTTCAATAACAGA & TTAAGTCTTCGTCCATCCATCC \\
\hline zola & GAACCCATCAACCGCATC & CGGGGCCCCTACATTTAC \\
\hline$z o 1 b$ & GAGGTCAAAGGGAAAGCTGA & CACGGAGTGGATGTCTGAAA \\
\hline claudin5a & TCCTGGGTCTGATCCTGTG & CTCGATGAAGGCGGTGAC \\
\hline nestin & TCGACAGACCAACACCAAAC & TGAGGCGATTGATCTGTGAC \\
\hline
\end{tabular}

were connected to a computerized image analysis system (NIS-Elements software; RRID: SCR_014329).

\section{Cell counting}

For analyzing constitutive neurogenesis, proliferative activity was determined by quantification of PCNAlabeled cells on images captured from at least three consecutive paraffin sections representative of a region of interest.

For analyzing injury-induced neurogenesis, counting was performed on 3-4 vibratome sections of $50 \mu \mathrm{m}$ thickness each in the injured versus uninjured telencephalon. Images were analyzed for detection of PCNApositive nuclei using ImageJ software (National Institutes of Health, Bethesda, MD; RRID: SCR_003070) by adjusting parameters (threshold, binary, and watershed) and running an analysis on "particles" taking into consideration the size and the circularity. Briefly, the parameters were set up as follows for each picture: threshold $=30-100$, particle size $=20-1,000$, circularity $=0.3-1.00$. Minor modifications in these parameters could be slightly adjusted according to the experiments. In addition, ImageJ automated selection of PCNA-positive nuclei was manually double-checked and adjusted if necessary for each picture. No significant difference was observed concerning the average size of counted particles in control versus hyperglycemic conditions (data not shown).

Neuroanatomical structures were identified with DAPI counterstaining according to the zebrafish brain atlas (Wullimann et al., 1996). Cell counting was performed in blind conditions by two different people on at least 2-4 independent experiments on a total of $n$ fish.

\section{Brain RNA extraction and reverse transcription}

Two whole mixed zebrafish (from a mixed-sex sampling zebrafish) brains were immediately removed from the skull, pooled, and stored at $-80^{\circ} \mathrm{C}$ prior to RNA extraction. Pools of brains were next grinded with
TissueLyser II (Qiagen, Chatsworth, CA) for RNA extraction using TRIzol reagent (Invitrogen, France). A total of $2 \mu \mathrm{g}$ of RNA was reverse transcribed to cDNA using random hexamer primers (Life Technologies) and MMLV reverse transcriptase (Invitrogen).

\section{Gene expression analysis by quantitative real-time polymerase chain reaction ( $q P C R$ )}

PCR experiments were performed with the AB 7500 real-time PCR system (Applied Biosystems, Foster City, CA) using the SYBR green master-mix (Eurogentec) and specific zebrafish primers (Table 2). Each PCR cycle was conducted for 15 seconds at $95^{\circ} \mathrm{C}$ and 1 minute at $60^{\circ} \mathrm{C}$. Melting curve analyses were performed to confirm correct amplification. Results were analyzed using the 7500 system SDS software (Applied Biosystems), and the relative expression of the claudin $5 a$, zo1a, zo $1 b$, il1 $\beta$, il6, il8, tnf $\alpha$, neurod4, and nestin genes was normalized against the expression level of the ef $1 \alpha$ gene.

\section{Statistical analysis}

Comparisons between groups were performed using a statistical Student's $t$-test. If more than two groups were analyzed, multiple testing was corrected by Benjamini-Hochberg. Error bars correspond to the standard error of the mean (SEM), and $n$ values correspond to the number of animals for all experiments. $P<0.05$ was considered statistically significant; ${ }^{\star} P \leq 0.05,{ }^{\star} * P$ $\leq 0.01$, and ${ }^{* *} P \leq 0.001$.

\section{RESULTS}

\section{Development of a new model of acute hyperglycemia in adult zebrafish}

We first investigated the effect of acute hyperglycemia (acute $H G$ ) on brain cell proliferation. For this purpose, we established a model of acute $H G$ by i.p. injection of D-glucose $(2.5 \mathrm{~g} / \mathrm{kg}$ of body weight). At 1 hour 30 minutes (1h30) post-injection (p.i.), zebrafish injected with D-glucose exhibited significantly higher 
TABLE 3.

Blood Glucose Measurement in the Acute and Chronic Hyperglycemic Models

\begin{tabular}{|c|c|c|}
\hline \multirow[b]{2}{*}{ Acute $H G$} & \multicolumn{2}{|c|}{ Blood glucose levels (mg/dl) } \\
\hline & $\begin{array}{c}1 \mathrm{~h} 30 \mathrm{p.i.} \\
\text { (2.5g D-glucose } / \mathrm{kg} \text { of body weight) }\end{array}$ & $\begin{array}{c}24 \mathrm{~h} \text { p.i. } \\
\text { (2.5g D-glucose } / \mathrm{kg} \text { of body weight) }\end{array}$ \\
\hline PBS & $149.8 \pm 27.8(n=4)$ & $97.8 \pm 16.3(n=21)$ \\
\hline AHG & $502.8 \pm 33.8(n=4)^{\star \star \star}$ & $94.2 \pm 13.1(n=26)$ \\
\hline Chronic HG & \multicolumn{2}{|c|}{ Blood glucose levels (mg/dl) (14 days in $111 \mathrm{mM} \mathrm{D-glucose)}$} \\
\hline $\begin{array}{l}\text { CTRL } \\
\text { CHG }\end{array}$ & \multicolumn{2}{|c|}{$\begin{array}{c}66.7 \pm 6.6(n=21) \\
281.6 \pm 30.1(n=24)^{\star \star \star}\end{array}$} \\
\hline
\end{tabular}

For acute HG experiments, adult zebrafish were intraperitoneally injected with PBS or with D-glucose. Glycemia was significantly increased in Dglucose injected fish at $1 \mathrm{~h} 30$ p.i. compared to controls $(P$-value $=0.0002)$, while no significant differences were observed between PBS and Dglucose-injected fish at $24 \mathrm{~h}$ p.i.

For chronic HG experiments, zebrafish were maintained in normal fish water (CTRL) while other zebrafish (chronic HG) were maintained in fish water supplemented with D-glucose $(111 \mathrm{mM})$ for 14 days. After the treatment, blood glucose levels are significantly higher in chronic HG fish. $* * * P \leq 0.0001 . n$ refers to the total number of fish.

blood glucose levels compared to the controls injected with the PBS vehicle only (Table $3 ; 502.8 \mathrm{mg} / \mathrm{dl} \pm$ 33.8 vs. $149.8 \mathrm{mg} / \mathrm{dl} \pm 27.8 ; n=4 ; P<0.0002 ; n=$ 4). Importantly, blood glucose levels were similar between the two groups at 24 hours p.i. (Table 3; 97.8 $\mathrm{mg} / \mathrm{dl} \pm 16.3$ vs. $94.2 \mathrm{mg} / \mathrm{dl} \pm 13.1 ; n=21$ for PBS and $n=26$ for acute $\mathrm{HG}$ ), showing that hyperglycemia was transient.

\section{Brain cell proliferation is not impaired by acute hyperglycemia in adult zebrafish}

To test our hypothesis that hyperglycemia may impact neural stem cell activity, we assessed brain proliferation after 24-hour acute HG p.i. by performing PCNA immunohistochemistry (Fig. 1). We thus focused our analysis on the ventricular regions that contain neural progenitors. We counted the number of PCNApositive cells at the junction between the olfactory bulbs $(\mathrm{OB})$ and the telencephalon (TEL) (Fig. 1A, OB/ $T E L)$; in the ventral nucleus of the ventral telencephalic area (Fig. 1B, Vv); in the dorsomedian telencephalon (Fig. 1C, Dm); in the periventricular pretectal nucleus (Fig. 1D, PPv); in the mediobasal hypothalamus, where the lateral recess starts to open (Fig. 1E, Hv LR); and in the caudal hypothalamus around the lateral and posterior recess of the diencephalic ventricle (Fig. 1F, LR PR). Acute HG did not impact neural stem cell proliferation in our experimental conditions, as further evidenced by PCNA and GFAP labeling at the OB/TEL junction, the $\mathrm{Vv} / \mathrm{Vd}$, and also in the PPv (Fig. $1 \mathrm{G}-\mathrm{L}$ ), even though a slight tendency for increased cell proliferation was observed in these regions except in the PPv (Fig. 1). In line with these observations, the gene expression of the neuronal marker neurod4 and the progenitors marker nestin was not altered in the brain of control (PBS) vs. acute HG fish at 24 hours p.i. (Fig. 2A).

\section{Acute hyperglycemia induces brain inflammation}

Hyperglycemia has been reported to induce the expression of proinflammatory cytokines and to increase BBB permeability in mammals (humans and rodents) (Esposito et al., 2002; Gyurko et al., 2006; Hawkins et al., 2007; Prasad et al., 2014). We thus tested the effects of acute HG on gene expression of inflammatory cytokines and proteins involved in the maintenance of BBB integrity. Our transcriptional analysis shows that acute $H G$ resulted in a significant increased expression of il1 $\beta(P=0.0042)$, il8 $(P=$ $0.019)$, and tnfo ( $P=0.015)$ (Fig. 2B). However, we did not observe any transcriptional change in the expression of genes encoding for proteins involved in BBB integrity, namely, claudin $5 a$ or zona occludens $1 a$ and 1b, under acute HG conditions (Fig. 2C).

\section{Chronic hyperglycemia impairs brain cell proliferation in adult zebrafish}

We next investigated the impact of chronic hyperglycemia on brain cell proliferation. For this purpose, zebrafish were kept in fish water supplemented with Dglucose (111 mM) for 14 days. This protocol was previously shown to increase blood glucose levels from a baseline of about $3 \mathrm{mM}(\sim 54 \mathrm{mg} / \mathrm{dl})$ to about $12 \mathrm{mM}$ $(\sim 216 \mathrm{mg} / \mathrm{dl})$ and to induce a wide variety of metabolic changes such as insulin resistance (Capiotti et al., 2014a). In our experimental conditions, after 14 days of this protocol, a significant proportion $(17 \%)$ of fish displayed normal glycemia $(<100 \mathrm{mg} / \mathrm{dl})$ and were consequently excluded, while most zebrafish (83\%) exhibited 
A
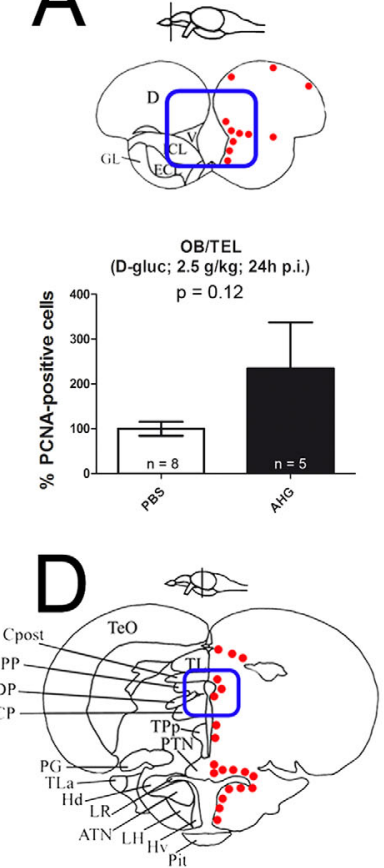

PPV
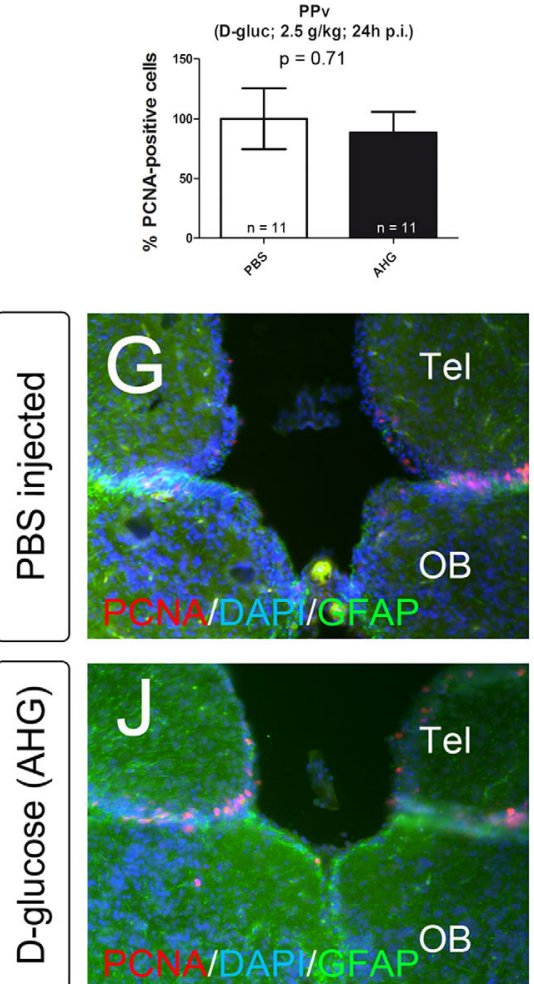

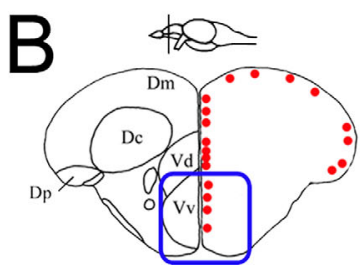

Vv

(D-gluc; $2.5 \mathrm{~g} / \mathrm{kg} ; 24 \mathrm{~h}$ p.i.) $p=0.61$
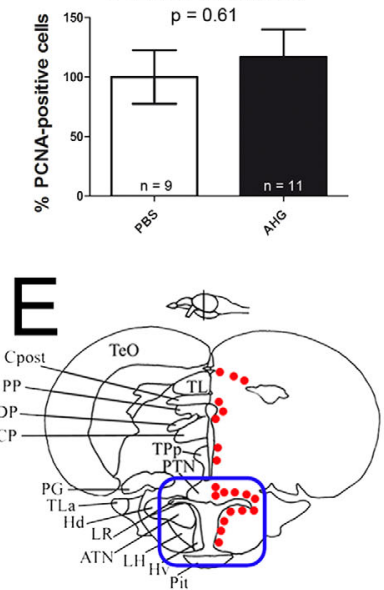

Hv LR
(D-gluc; $2.5 \mathrm{~g} / \mathrm{kg} ; 24 \mathrm{~h}$ p.i.)
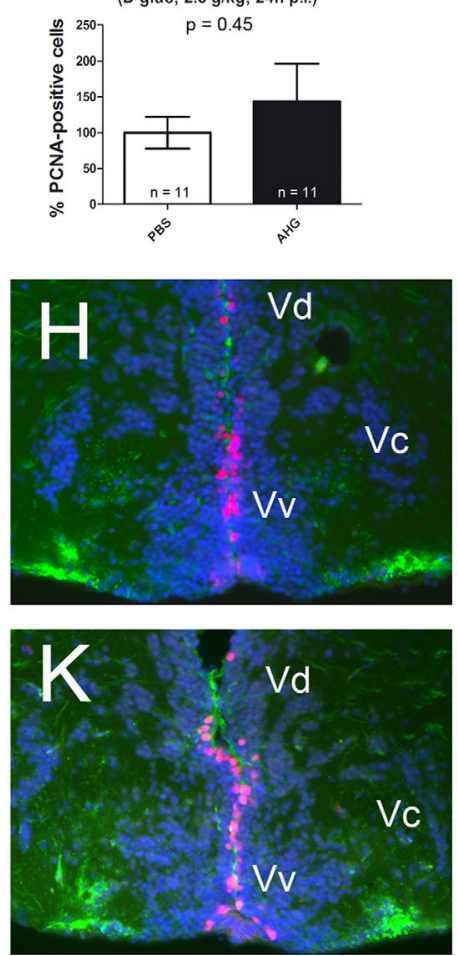

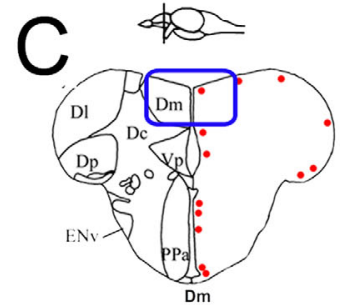

(D-gluc; $2.5 \mathrm{~g} / \mathrm{kg} ; 24 \mathrm{~h}$ p.i.)
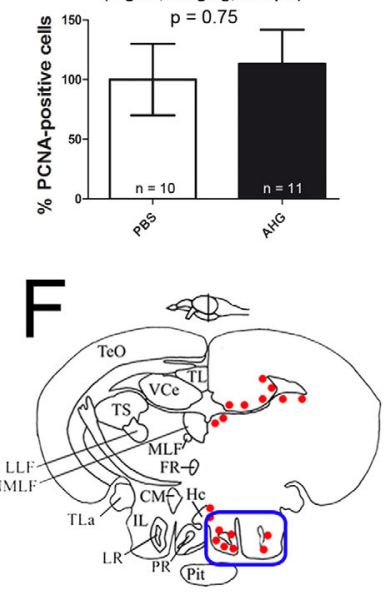

LRPR
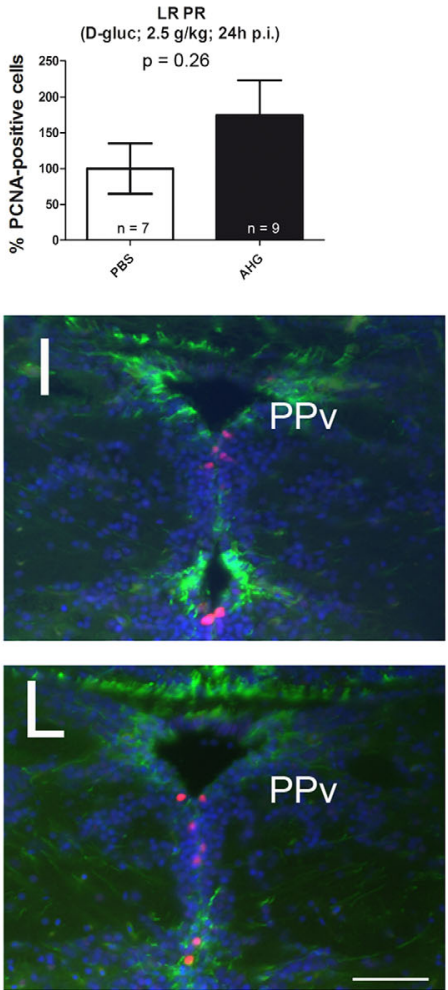

Figure 1. Acute hyperglycemia does not impair brain cell proliferation. A-F: Statistical analysis of proliferative cells in control (PBS) and acute HG (AHG) zebrafish at 24 hours p.i. by performing PCNA immunohistochemistry. Schematic representations taken from the zebrafish brain atlas (Wullimann et al., 1996) show the different regions of interest and the proliferative cells (red dots) as previously described in the literature (Zupanc et al., 2005; Pellegrini et al., 2007). Blue boxes highlight regions where the number of proliferative cells (PCNA-positive) was counted. No significant difference in proliferative activity was observed between PBS- and D-glucose-injected zebrafish in the OB/TEL (A), Vv (B), Dm (C), PPv (D), mediobasal hypothalamus (E), and caudal hypothalamus (F). G-L: Representative digital pictures of PCNA (red) and GFAP (green, a radial glial marker) immunohistochemistry on paraffin brain sections of PBS- and D-glucose-injected zebrafish (24 hours p.i.) counterstained with DAPI. Pictures were taken with an epifluorescence microscope. Error bars correspond to the standard error of the mean (SEM) and $n$ refers to the total number of fish. Scale bar $=70 \mu \mathrm{m}$. 
significantly higher blood glucose levels (>100 mg/dl) compared to control fish (Table 3; $281.6 \mathrm{mg} / \mathrm{dl} \pm 30.1$ $[n=24]$ vs. $66.7 \mathrm{mg} / \mathrm{dl} \pm 6.6[n=21])$. We then examined the effect of chronic $\mathrm{HG}$ on brain cell proliferation by performing PCNA immunohistochemistry in the above-described regions (Fig. 3). In contrast to acute $H G$, chronic $H G$ resulted in a significant decrease in
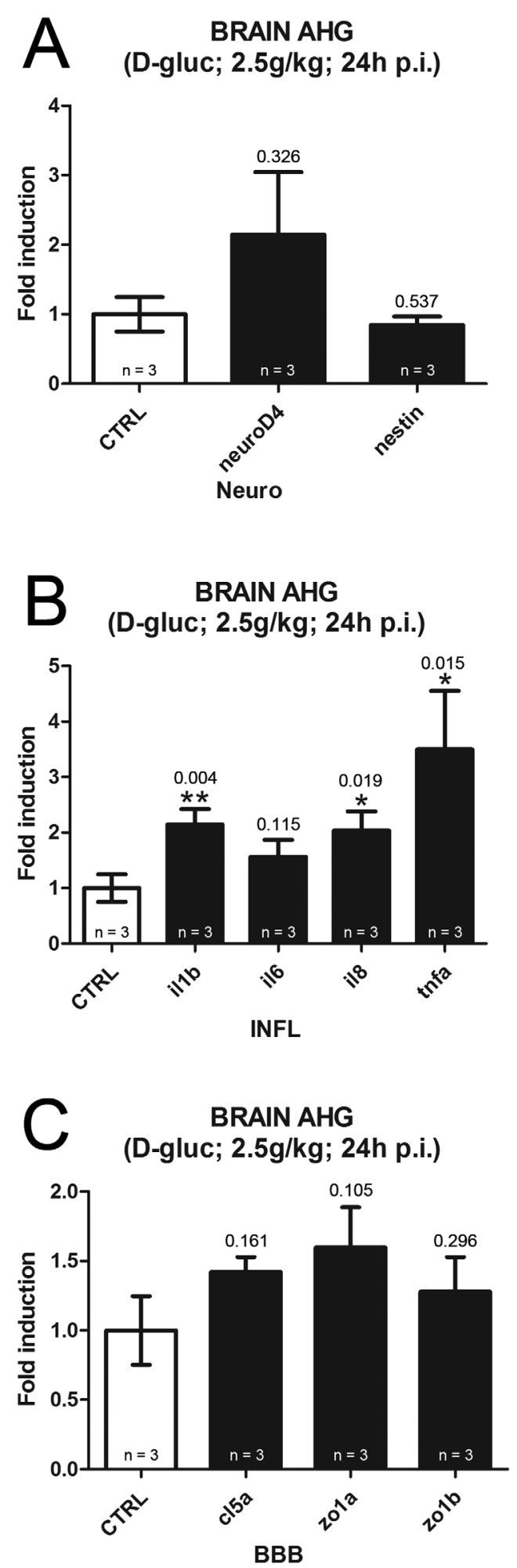

ventricular proliferation in most of the examined regions (Fig. 3). Indeed, chronic HG zebrafish displayed an almost 50\% reduction in PCNA-positive cells in the anterior part of the brain, at the OB/TEL junction (Fig. $3 \mathrm{~A}, \mathrm{~A} 1, P=0.0008)$, in the ventral nucleus of the ventral telencephalic area (Fig. 3B, B1, $P=0.0009$ ), and in the dorsomedian telencephalon (Fig. 3C, C1, $P=$ $0.001)$. In more posterior regions, such as in the periventricular pretectal nucleus (PPv) localized just below the posterior commissure (Cpost), we observed a $63 \%$ reduction in the number of PCNA-positive cells in chronic HG-treated fish relative to control (Fig. 3D, D1, $P=0.0011)$. In the diencephalon, including the anterior part of the preoptic area (data not shown) and the mediobasal and caudal hypothalamus (Fig. 3E, E1, $3 F, F 1)$, we observed no significant difference of proliferation between the two groups (33\% decrease for $\mathrm{Hv}$ $\mathrm{LR}, P=0.08$; and $24 \%$ for LR PR, $P=0.16$ ). Similar to the acute $H G$ condition, neurod4 and nestin gene expression was unaltered in chronic $H G$ fish compared to control (Fig. 4A).

\section{Chronic hyperglycemia increased zo1a and zo1b gene expression}

Expression of $i l 1 \beta$, il6, il8, and $t n f \alpha$ was not modulated after a 14-day chronic hyperglycemic treatment (Fig. 4B). However, chronic HG-treated fish displayed a significant upregulation of zona occludens $1 a$ and $1 b$, suggesting that chronic hyperglycemia may have an impact on the physiology of the BBB (Fig. 4C).

\section{Chronic hyperglycemia impairs the regenerative neurogenesis after stab wounding in the adult telencephalon}

In the last part of our study, we aimed at investigating the impact of acute and chronic hyperglycemia on

Figure 2. Gene expression of proinflammatory cytokines and tight junctions in the brain of fish following acute hyperglycemia. Semiquantitative PCR analysis in the brain of adult zebrafish following acute hyperglycemia (24 hours p.i.). A: The neuronal and progenitor marker expression, neurod4 and nestin, is not significantly modulated at 24 hours p.i. B: Acute hyperglycemia upregulates proinflammatory cytokines gene expression of il1 $\beta$, il6, il8, and tnf $\alpha$ at 24 hours p.i. This increase is statistically significant for il1 $\beta$, il8, and $\operatorname{tnf} \alpha(P=0.0042$ for $i l 1 \beta, 0.019$ for il8, 0.015 for $\operatorname{tnf} \alpha$ ). C: Acute hyperglycemia does not significantly modulate gene expression of claudin $5 a(c / 5 a)$ or zona occludens $1 a$ and $1 b$ (zo1a and zo1b), encoding for proteins involved in the maintenance of the blood-brain barrier. ${ }^{\star} P \leq 0.05,{ }^{*} P \leq 0.01$ and $\star \star \star P \leq 0.001$. Error bars correspond to the standard error of the mean (SEM) and $n$ refers to the total number of two pooled zebrafish brains. 
A
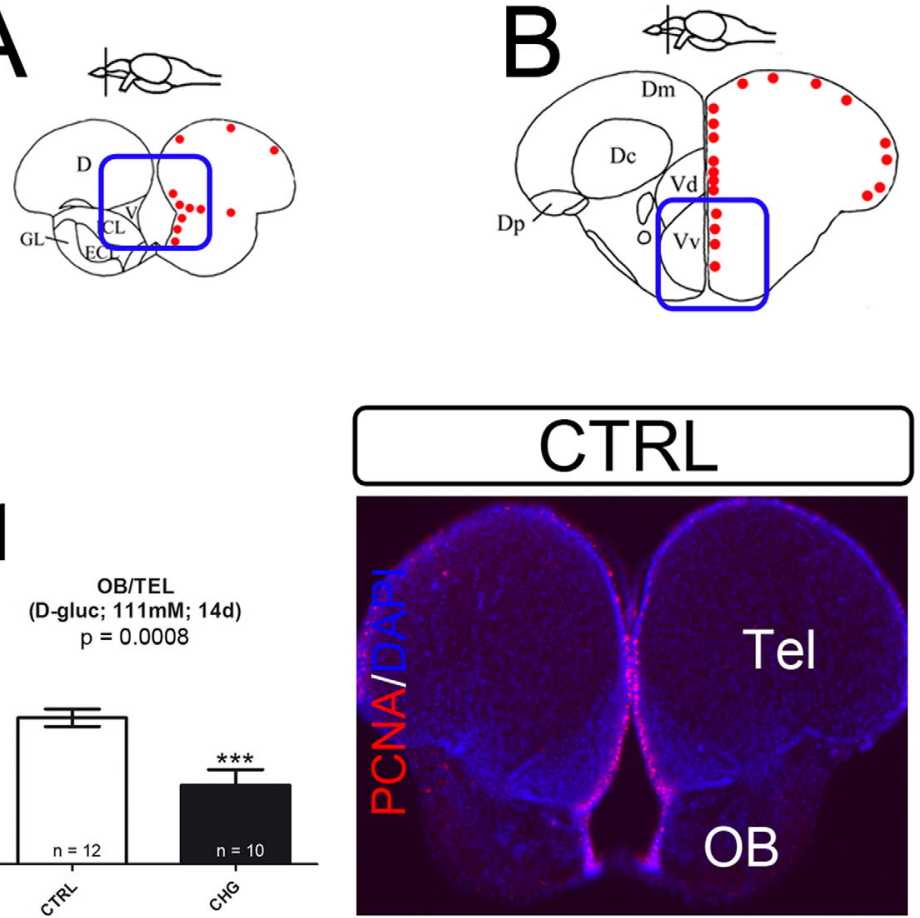

B1

A1

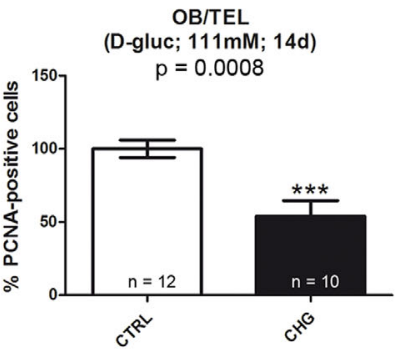

Vv

(D-gluc; $111 \mathrm{mM} ; 14 \mathrm{~d}$ )

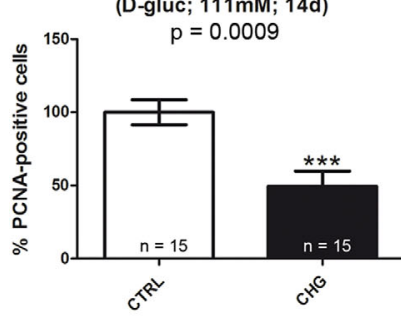

C1

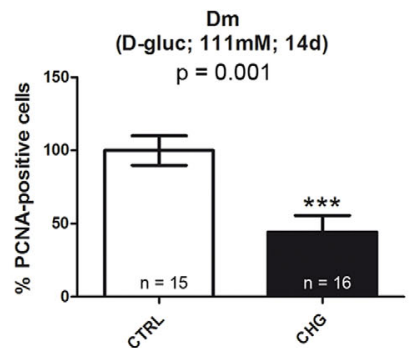

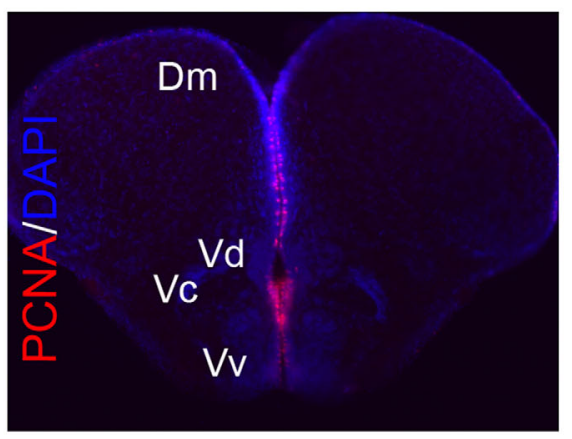

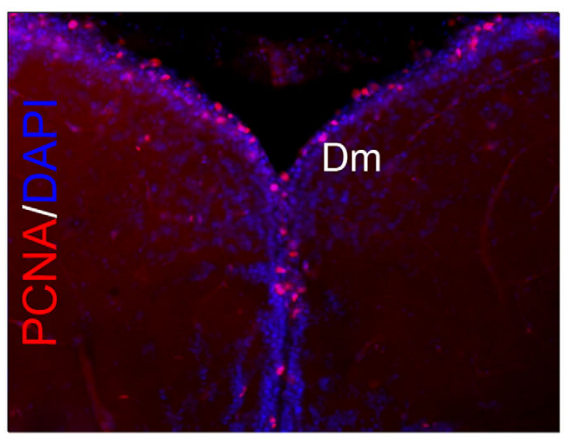

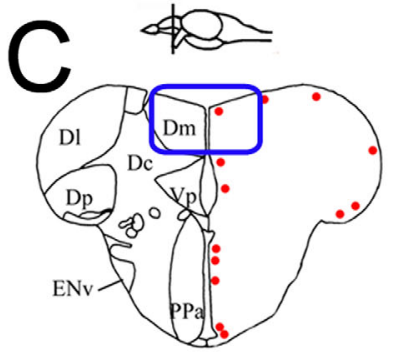
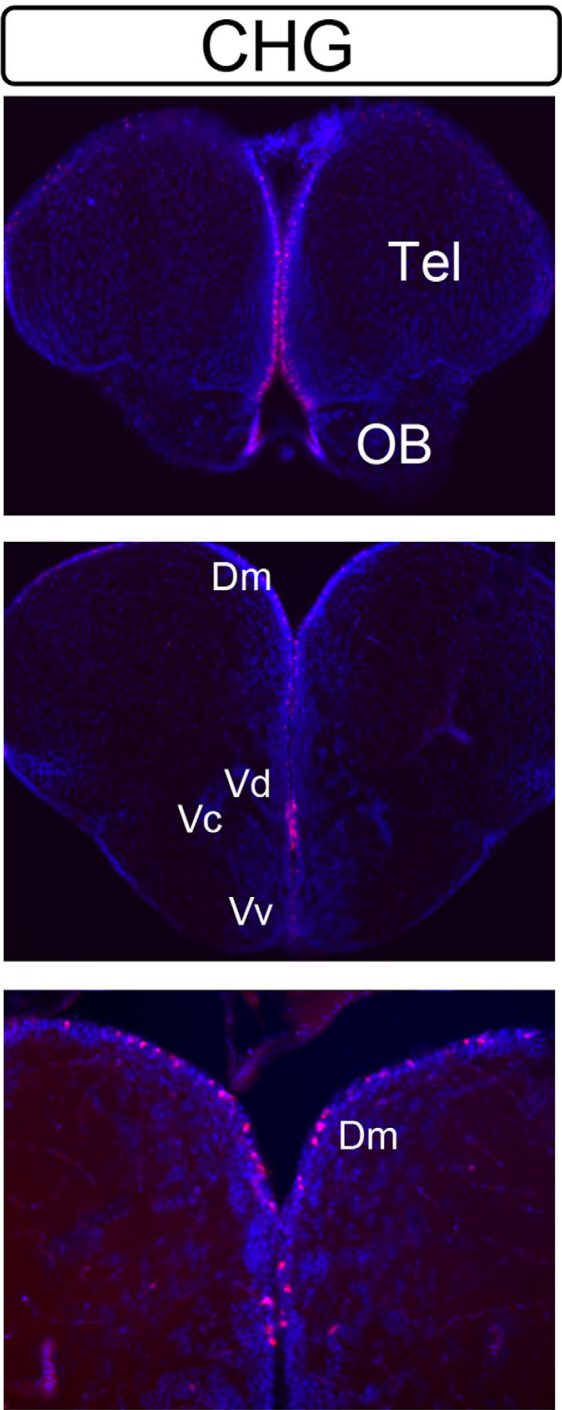

Figure 3. Chronic hyperglycemia results in a significant decrease in neural progenitor proliferation. A-F: Schematic representations taken from the zebrafish brain atlas (Wullimann et al., 1996) show the different regions of interest and the proliferative cells (red dots) as previously described in the literature. Blue boxes highlight the regions where the number of proliferative cells (PCNA-positive) was counted. A1-F1: Statistical analysis of proliferative cells (PCNA-positive) in the forebrain of control (CTRL) and CHG (D-glucose; $111 \mathrm{mM}$; 14d) zebrafish. The number of proliferative cells was decreased by around $50 \%$ at the OB/TEL junction $(\mathrm{A} 1, P=0.0008)$ and in the $\mathrm{Vv}(\mathrm{B} 1, P=0.0009), \mathrm{Dm}(\mathrm{C} 1, P=$ $0.001)$, and PPv (D1, $P=0.0011)$. In the hypothalamus, brain cell proliferation was also decreased, but not significantly, at the opening of the lateral recess $(\mathrm{E} 1, P=0.0861)$ and around the lateral and posterior recess $(\mathrm{F} 1, P=0.1687)$. The representative digital pictures of PCNA (red) immunohistochemistry staining at the OB/TEL junction, the Vv, the Dm, the PPv, the Hv LR, and the LR PR regions with DAPI (blue) counterstaining show a decrease in proliferation under chronic HG. Error bars correspond to the standard error of the mean (SEM). These data were obtained from four independent experiments, with $n$ referring to the total number of fish. Pictures of vibratome sections were taken with an epifluorescence microscope. ${ }^{* *} P \leq 0.01$ and ${ }^{* *}{ }^{*} P \leq 0.001$. Scale bar $=70 \mu \mathrm{m}(\mathrm{H}) ; 100 \mu \mathrm{m}(\mathrm{L}) ; 140 \mu \mathrm{m}(\mathrm{F}) ; 220 \mu \mathrm{m}(\mathrm{B}, \mathrm{D}, \mathrm{J})$. 

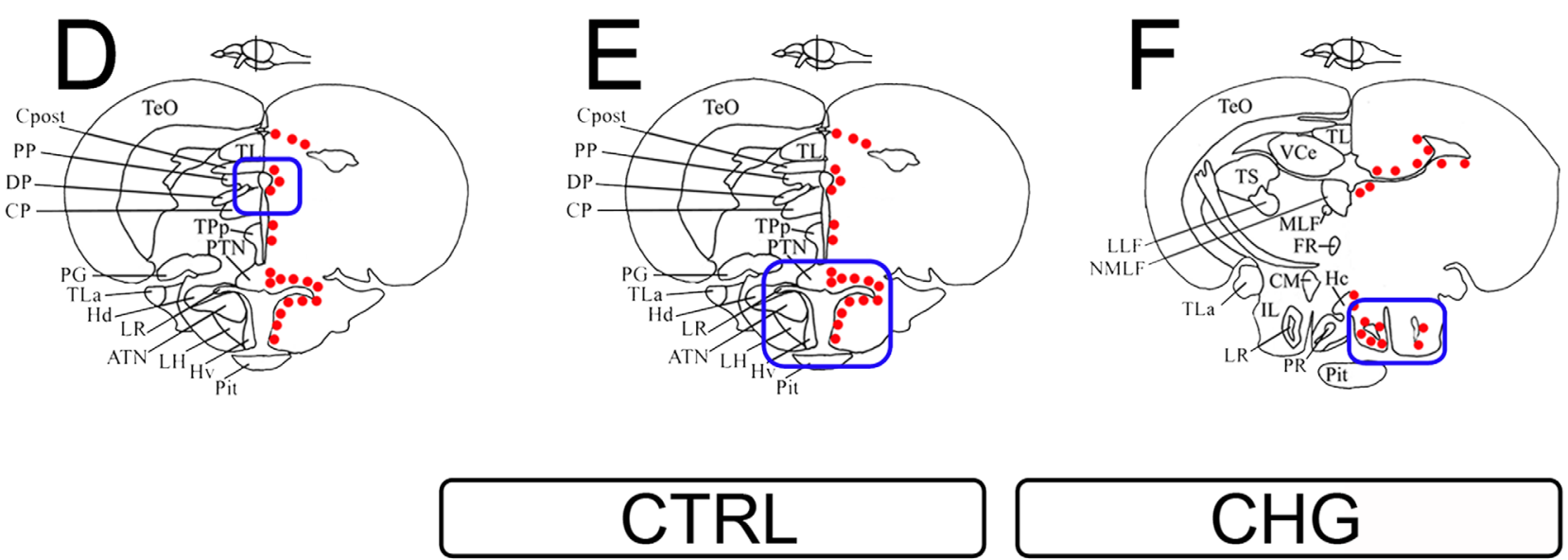
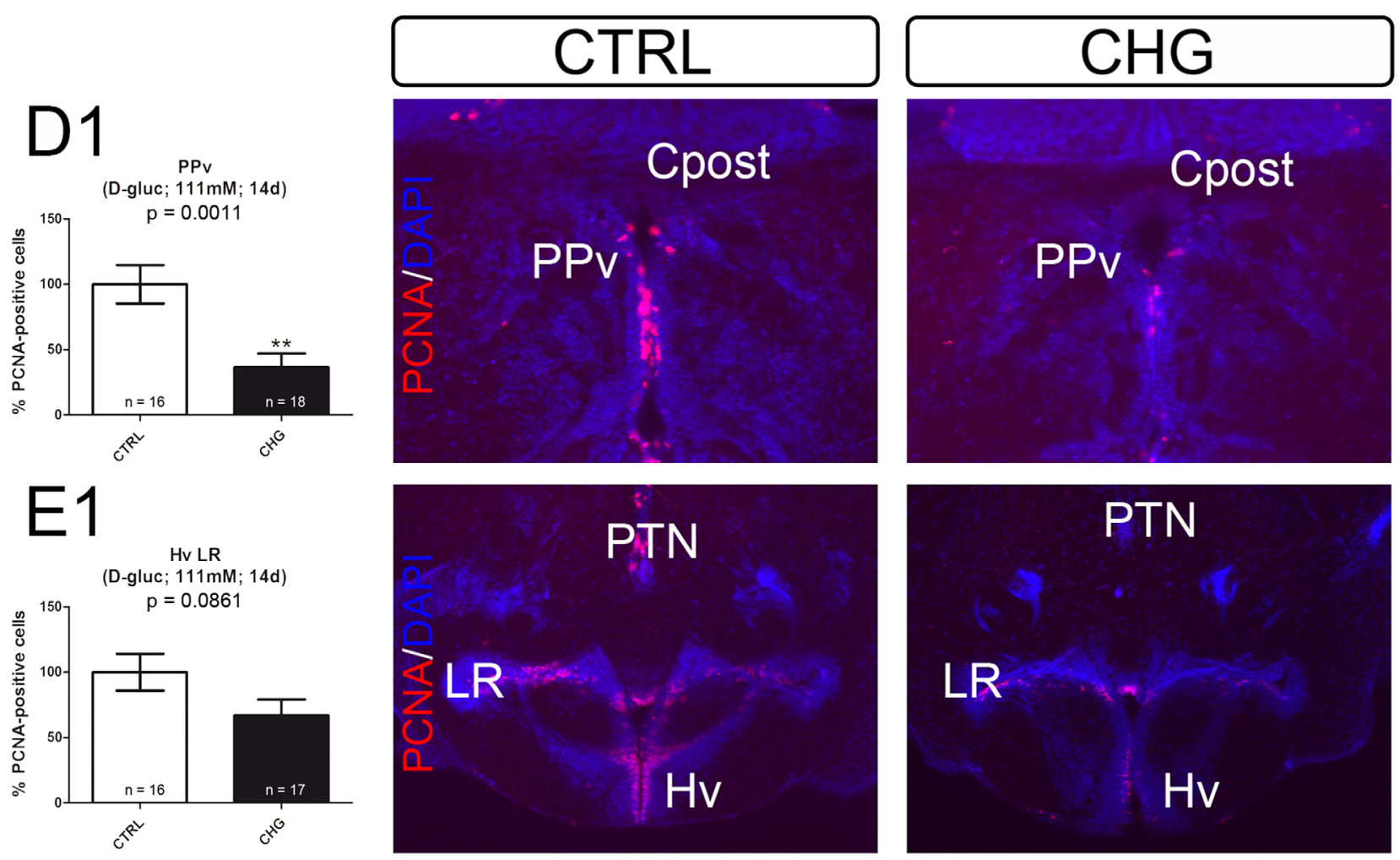

\section{F1}
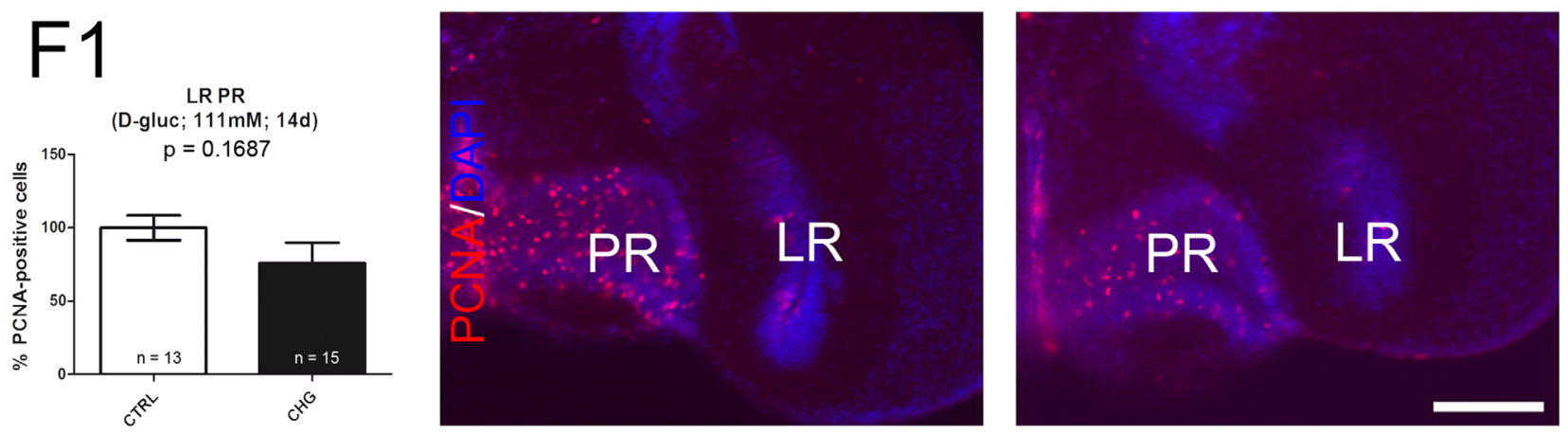

Figure 3. Continued.

brain cell proliferation during brain repair. For this purpose, the telencephalon was submitted to a mechanical injury, following an established procedure (Ayari et al., 2010; Diotel et al., 2010a). It has been reported that at
1 day postlesion ( $d p l)$, the first proliferating cells are microglial cells and oligodendrocytes, which are localized in the brain parenchyma (März et al., 2011), whereas from 3 to $7 \mathrm{dpl}$, proliferative cells are localized 
along the brain ventricles and can be identified as radial glia cells that give rise to new neurons (März et al., 2011; Baumgart et al., 2012). We thus investigated the effects of acute hyperglycemia on proliferation in the brain parenchyma and the effects of chronic hyperglycemia on proliferation along the ventricular layer. In
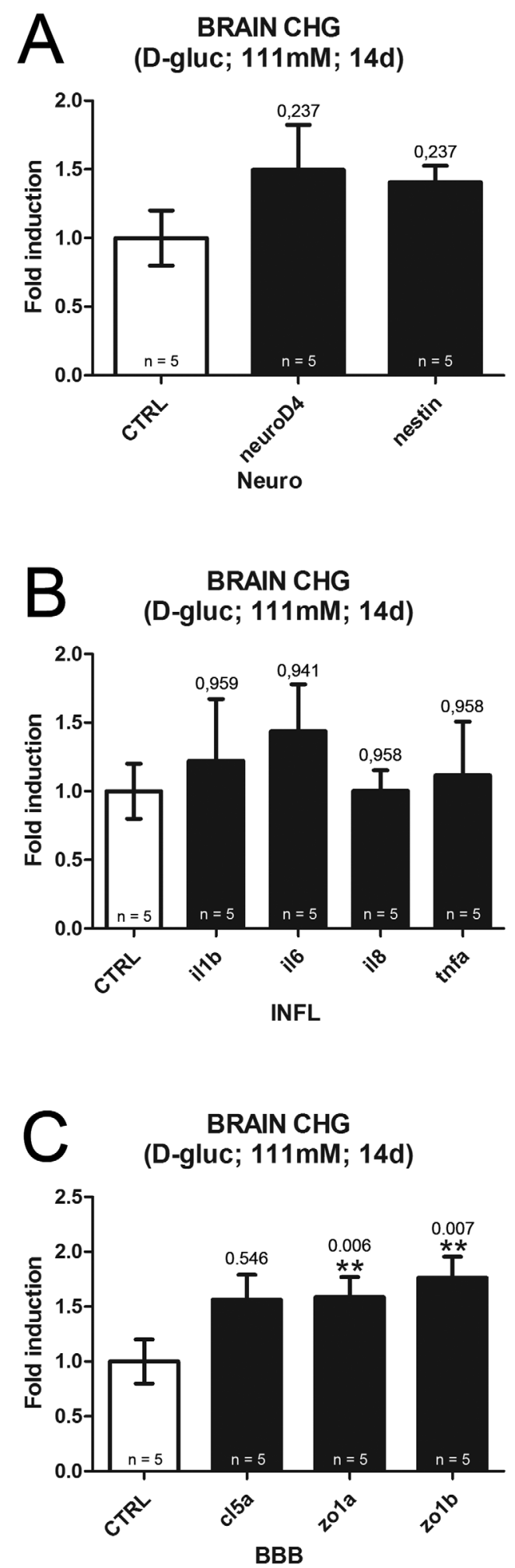

both normoglycemic and acute HG conditions (24 hours p.i. and $1 \mathrm{dpl}$ ), the number of PCNA-positive cells increased by almost two times in the injured telencephalon (Fig. 5A,C). This observation indicates that acute HG does not impair the initial step of parenchymal brain cell proliferation.

We next analyzed the effect of chronic HG on the proliferation of ventricular cells mainly corresponding to radial glial cells (type 1 and 2 progenitors; type 1 corresponding to quiescent radial glia and type 2 to actively dividing radial glia). Therefore, we stab wounded fish after 7 days of chronic $\mathrm{HG}$ and allowed them to survive for 1 week in chronic HG conditions. In control and chronic HG conditions, we observed a significant increase in cell proliferation in the ipsilateral hemisphere compared to the contralateral one (Fig. 5B,D). Interestingly, injury-induced ventricular proliferation was significantly reduced in chronic HG-treated fish compared to control fish (Fig. 5B,D; $P=0.0127$ ). Consequently, our results clearly show that hyperglycemia impairs recruitment and/or activation of radial glial cells following stab wound injury.

\section{DISCUSSION}

In the central nervous system, dysglycemia is known for impairing synaptic transmission, neural plasticity, and cognition (Mooradian, 1997a,b; Kodl and Seaquist, 2008; Wang et al., 2012; Ho et al., 2013; Prasad et al., 2014). It has been reported that more than $50 \%$ of patients admitted for ischemic stroke experience hyperglycemia (Scott et al., 1999; Capes et al., 2001), whether due to stress or type 2 diabetes, and that hyperglycemia is associated with poor clinical outcome after thrombolysis (Desilles et al., 2013).

In the present study, we investigated the impact of acute and chronic hyperglycemia on adult zebrafish neurogenesis and brain homeostasis. Our results showed that brain homeostasis was differently affected in acute $\mathrm{HG}$ and chronic $H G$ conditions. Indeed, acute $H G$ led to brain

Figure 4. Proinflammatory cytokines and BBB gene expression following chronic hyperglycemia. Semiquantitative PCR analysis in the brain of adult zebrafish following chronic hyperglycemia (Dglucose; $111 \mathrm{mM}$; 14d). A,B: Chronic hyperglycemia treatment did not modulate expression of the neuronal and progenitor markers, neurod4 and nestin, respectively, or those of the proinflammatory cytokines il $1 \beta$, il6, il8, and tnf $\alpha$. C: Chronic hyperglycemia treatment results in a significant upregulation of zona occludens $1 a$ and $1 b$ (zo1a and zo1b, $P=0.006$ and 0.007 , respectively), involved in the maintenance of the BBB. Although claudin $5 a$ gene expression is not significantly modulated, it shows an increasing trend. ${ }^{*} P \leq 0.01$. Error bars correspond to the standard error of the mean (SEM) and $n$ refers to the total number of two pooled zebrafish brains. 


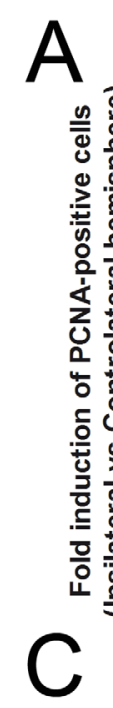

Stabwounded brain
(24h p.i. ; $1 \mathrm{dpl})$
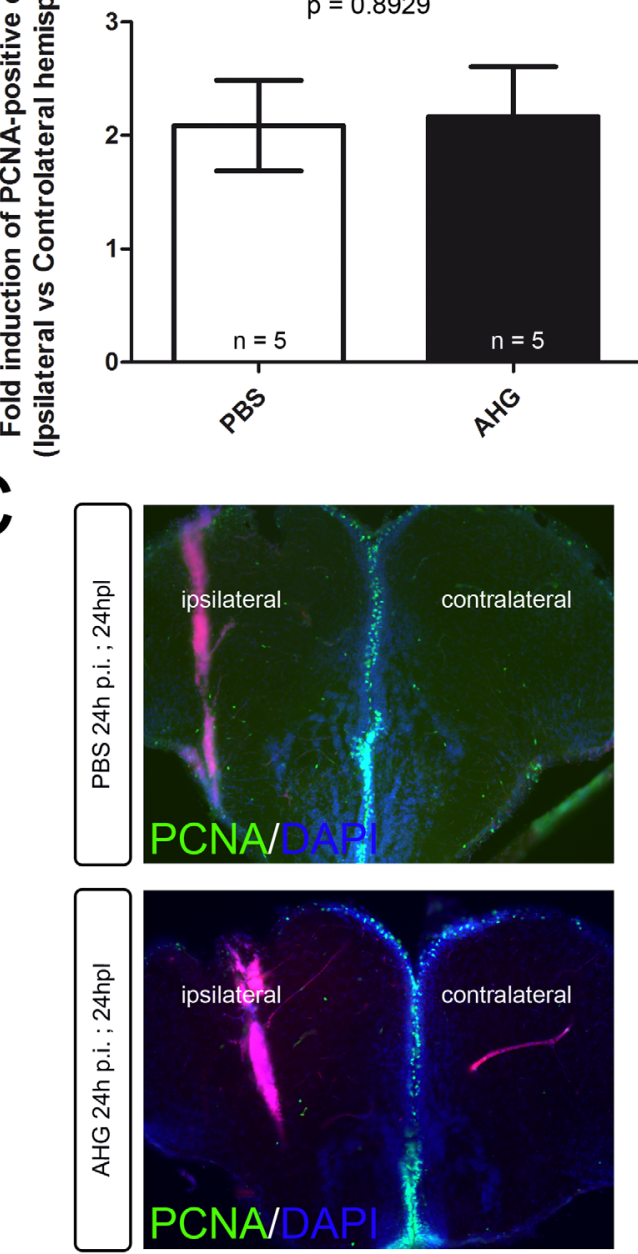

$\mathrm{B}$
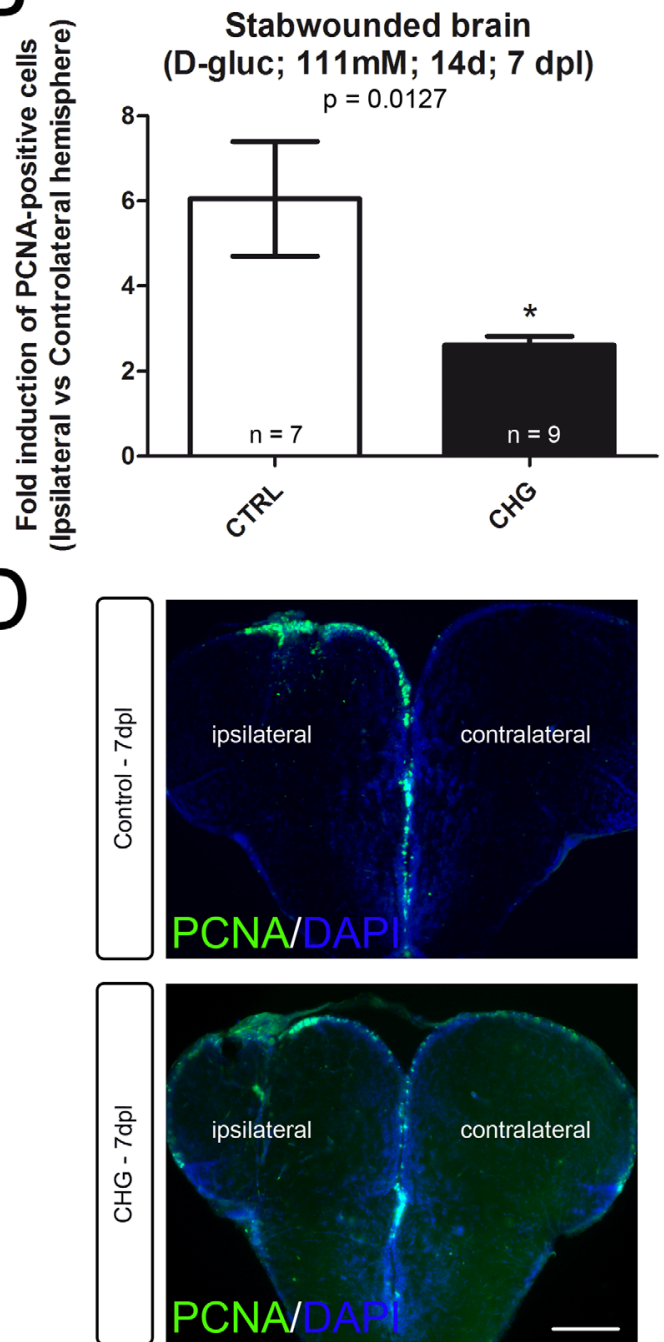

Figure 5. Chronic hyperglycemia impairs brain cell proliferation after stab wounding injury of the telencephalon. A: Fold induction of PCNApositive cells (ipsilateral vs. contralateral) in PBS- and D-glucose- $(2.5 \mathrm{~g} / \mathrm{kg}$ of body weight) injected fish at 24 hours post-injection (p.i.) and 1 day post-lesion (dpl). B: Fold induction of PCNA-positive cells (ipsilateral vs. contralateral) in control fish and chronic HG-treated fish (111 $\mathrm{mM}$ D-glucose; 14 days) with stab wounding at day 7. Ventricular cell proliferation induction after stab wounding is significantly decreased in chronic HG-treated fish ( $P=0.0127)$. C,D: PCNA immunohistochemistry (green) and DAPI counterstaining (blue) on vibratome brain sections of 24 hours stab-wounded telencephalon of PBS- and D-glucose- $(2.5 \mathrm{~g} / \mathrm{kg}$ of body weight) injected fish (C), and of chronic HG-treated fish (111 mM D-glucose; 14 days) stab-wounded at 7 days of treatment and allowed to survive for 7 days in chronic HG conditions. A decrease in ventricular cell proliferation is observed under chronic HG conditions. Pictures were taken with an epifluorescence microscope. ${ }^{\star} P \leq 0.05$. Error bars correspond to the standard error of the mean (SEM) and $\mathrm{n}$ refers to the total number of fish. Scale bar $=220 \mu \mathrm{m}$.

inflammation without impairing adult neurogenesis, whereas chronic HG resulted in a significant decrease in cell proliferation along the brain ventricle, where neural stem cells and further committed progenitors are localized. Finally, we showed that chronic HG markedly reduced neurogenesis following stab wound injury in the brain of adult zebrafish.

\section{Hyperglycemia}

As shown in our experimental conditions, both acute i.p. injection and chronic exposure to D-glucose in the fish water induced hyperglycemia (Table 3). We observed significantly higher blood glucose levels for acute HG zebrafish 1 h30 after D-glucose injection compared to control fish (Table 3). We also observed an increasing trend in blood sugar level in PBS-injected fish at 1 h30 p.i. compared to baseline glycemia, which could be attributed to stress induced by the injection and/or the use of the anesthetic that is known to induce a wide variation of blood glucose levels (Chavin and Young, 1970; Eames et al., 2010). As expected, at 24 hours p.i., D-glucose-injected fish displayed 
normoglycemic values (Table 3). Therefore, blood glucose levels appear to be dynamically regulated in zebrafish, as previously shown (Chavin and Young, 1970; Eames et al., 2010).

To our knowledge, this is the first description of an acute hyperglycemia model in zebrafish. We also validated the chronic HG model, as zebrafish immersed in Dglucose water (111 mM for 14 days) became hyperglycemic. This is consistent with previous studies from Capiotti et al. (2014) showing an increase in blood glucose level that correlates with the time of immersion in Dglucose supplemented water (Capiotti et al., 2014a). Under such conditions, it was found that hyperglycemia had already been induced starting from 3 days of treatment (Capiotti et al., 2014a). Interestingly, i.p. D-glucose injection induced a peak of hyperglycemia at $\sim 500 \mathrm{mg} /$ $\mathrm{dL}$, whereas acute exposure to D-glucose led to a glycemia of $\sim 280 \mathrm{mg} / \mathrm{dl}$. Taken together, these data further strengthen the utility of our procedures as relevant models for studying acute HG and chronic HG. Importantly, we noticed that, in some experiments, not all the fish displayed hyperglycemia after the chronic immersion in D-glucose (data not shown; 17\% nonhyperglycemic vs. $83 \%$ hyperglycemic). This might be due to different susceptibilities of the individual fish to hyperglycemia according to age or compensatory mechanisms (Sarras and Intine, 2013; Connaughton et al., 2016).

\section{Inflammation and BBB}

In the brain of acute HG fish, we noticed an increase in proinflammatory cytokine expression (il1 $\beta$, il6, il/, and $t$ th $\alpha$ ), reaching statistical significance for $i / 1 \beta$, il/, and tnfo (Fig. 2B). Such proinflammatory effects of hyperglycemia are already well-characterized in mammals in a wide variety of tissues, including tissues of the central nervous system (Esposito et al., 2002; Lin et al., 2005; Gyurko et al., 2006). Proinflammatory cytokines are important mediators of the early immune response and display pleiotropic effects such as promoting immune cell proliferation (Randelli et al., 2008) and modulating neuronal survival and neurogenesis (Fuster-Matanzo et al., 2013; Tobin et al., 2014; Borsini et al., 2015). In our experimental conditions, proinflammatory cytokine gene expression was unchanged in the brain of chronic HG zebrafish after 14 days (Fig. 4A). This finding does not preclude the possibility that the expression of these genes is modulated within the first days of chronic HG, but that an adaptive response may take place to counteract chronic inflammation, particularly in light of the zebrafish's high capacity for adaptation and regeneration (Randelli et al., 2008). Such presumed compensatory mechanisms will require further investigation.
Regarding the BBB, claudin $5 a$ and zona occludens $1 a$ or $1 \mathrm{~b}$ gene expression was not modulated under acute HG at 24 hours p.i. (Fig. 2B), but zona occludens $1 a$ and 16 gene expression was significantly upregulated under chronic HG (Fig. 4B). Our results show that chronic hyperglycemia affects the expression of genes involved in $B B B$ establishment. However, our attempts at testing for BBB leakage using Evans blue dye were not conclusive due to a wide variability in staining (data not shown). Numerous in vitro and in vivo studies have demonstrated that hyperglycemia increases BBB leakage by downregulating tight junction protein expression (e.g., occludin and zona occludens-1) (Chehade et al., 2002; Hawkins et al., 2007; Ergul et al., 2009; Chao et al., 2016). Indeed, type 2 diabetes rats were reported to display an impaired hippocampal BBB (Yoo et al., 2016). In zebrafish, the blood-retinal barrier was equally impacted by hyperglycemia during development, as shown by abnormalities in blood vessels morphology and decreased levels of ZO-1 protein expression (Alvarez et al., 2010; Jung et al., 2016). We hypothesized that the zona occludens $1 a$ and $1 b$ upregulation could be due to compensatory mechanisms in response to BBB aggression.

\section{Neurogenesis}

In our experiments, acute HG did not impair neural stem cell proliferation in the different brain regions or nuclei studied (Fig. 1); however, chronic HG-treated fish exhibited a significant decrease in ventricular proliferation in all regions studied (OB/TEL, Vv, Dm, PPv) except the mediobasal (Hv LR) and caudal hypothalamus (LR PR). Nevertheless, the hypothalamus displays a consistent decrease in cell proliferation (Fig. 3). Our observations are in line with previous reports in mammals showing that type 2 diabetes-associated oxidative stress and/or inflammation inhibit hippocampal proliferation and neuronal migration and promote neuronal death (Beauquis et al., 2006; Wiltrout et al., 2007; Jakubs et al., 2008; Stranahan et al., 2008; Yi et al., 2009; Ho et al., 2013). High glucose levels were also shown to induce deleterious effects on embryonic quail neurogenesis, by decreasing neurite length and neuronal migration, and by increasing reactive oxidative species generation (Chen et al., 2013). In both acute HG and chronic HG conditions, neurod4 and nestin gene expression remained unchanged, suggesting no influence of either acute or chronic hyperglycemia on neuronal differentiation and neural progenitor levels (Figs. 2A, 4A). However, further investigations should elucidate how hyperglycemia impacts neurogenic processes.

Brain regeneration in zebrafish has been well characterized. It starts with an initial parenchymal proliferation of microglial cells and oligodendrocytes (day 1 to 3 ) that is followed by a highly sustained proliferation of 
radial glial cells in the ventricular layer from 3 days post-injury, allowing the production of new neurons (Kaslin et al., 2008; Kroehne et al., 2011; März et al., 2011; Diotel et al., 2013; Alunni and Bally-Cuif, 2016). By performing stab wound injury of the telencephalon, we showed that acute HG did not impair the initial step of parenchymal brain cell proliferation but that chronic HG disrupted the ventricular cell proliferation at 7 days post-injury. Such a deleterious effect of hyperglycemia in regenerative mechanisms is consistent with the wellknown complications of type 2 diabetes relating to impaired wound healing (Rosenberg, 1990; Lioupis, 2005). In zebrafish, hyperglycemia was also shown to affect the healing process during fin regeneration (Olsen et al., 2010). Additionally, numerous studies have documented the adverse effects of hyperglycemia/diabetes on brain stoke and traumatic brain injury (Cherian et al., 1997; Huang et al., 2013; Jauch-Chara and Oltmanns, 2014).

It is interesting to note that diabetes is also known for impairing brain memory (Whitmer, 2007; Ho et al., 2013). Recently, using the same experimental conditions, Capiotti and colleagues demonstrated that hyperglycemia induces memory impairment in adult zebrafish (Capiotti et al., 2014b), similar to the mammalian situation. Taken together, these data demonstrate that hyperglycemia in zebrafish impairs brain functions such as neurogenesis and memory.

Such adverse effects of hyperglycemia on brain cell proliferation have probably multiple direct and/or indirect origins. By increasing brain inflammation and by disrupting the BBB, hyperglycemia could favor the central effects of peripheral factors such as proinflammatory cytokines and adipokines that have been documented to disrupt neural stem cell activity (Arnoldussen et al., 2014; Letra et al., 2014; Parimisetty et al., 2016). Hyperglycemia is also known for inducing an increase in advanced glycation endproducts that is correlated with decreased hippocampal neurogenesis in STZ-induced diabetic rats (Ho et al., 2013). Variation of insulin and/or IGF-1 levels resulting from hyperglycemia could also be factors modulating the activity of neural stem cells (Rafalski and Brunet, 2011; Ziegler et al., 2015). Taken together, these data highlight the necessity of further investigations in order to understand the mechanistic behind the decreased proliferation observed in our model.

\section{CONCLUSION}

In the present study, we demonstrate that hyperglycemia disturbs brain homeostasis, influencing brain inflammation and neurogenesis in homeostatic and in injury-induced conditions. Taken together, our data and those reported by Capiotti and colleagues highlight an evolutionary-conserved impact of hyperglycemia on brain homeostasis and plasticity. Finally, this work confirms the value of the zebrafish model in studying the effects of hyperglycemia on the central nervous system, particularly in pathological situations such as stroke.

\section{ACKNOWLEDGMENTS}

We thank Dr. Wildriss Viranaicken for help in providing reagents and advice, and Janice Tailé for technical support. We thank Dr. Benjamin Weger for scientific discussion and critically reading the article.

\section{CONFLICT OF INTEREST}

The authors declare that they have no competing interest.

\section{AUTHOR CONTRIBUTIONS}

Conception and design of the experiments: ND, OM, CLDH, ACD, MW, EB. Acquisition of data: ACD, ND, SS. Analysis of the data: ND, ACD, SS, CLDH, OM, MW, EB.

\section{LITERATURE CITED}

Adolf B, Chapouton P, Lam CS, Topp S, Tannhauser B, Strähle U, Götz M, Bally-Cuif L. 2006. Conserved and acquired features of adult neurogenesis in the zebrafish telencephalon. Dev Biol 295:278-293.

Alunni A, Bally-Cuif L. 2016. A comparative view of regenerative neurogenesis in vertebrates. Development 143:741753.

Alvarez Y, Chen K, Reynolds AL, Waghorne N, O'Connor JJ, Kennedy BN. 2010. Predominant cone photoreceptor dysfunction in a hyperglycaemic model of nonproliferative diabetic retinopathy. Dis Models Mech 3: 236-245.

Arnoldussen IA, Kiliaan AJ, Gustafson DR. 2014. Obesity and dementia: adipokines interact with the brain. Eur Neuropsychopharmacol 24:1982-1999.

Ayari B, El Hachimi KH, Yanicostas C, Landoulsi A, SoussiYanicostas N. 2010. Prokineticin 2 expression is associated with neural repair of injured adult zebrafish telencephalon. J Neurotrauma 27:959-972.

Batailler M, Droguerre M, Baroncini M, Fontaine C, Prevot V, Migaud M. 2014. DCX-expressing cells in the vicinity of the hypothalamic neurogenic niche: a comparative study between mouse, sheep, and human tissues. J Comp Neurol 522:1966-1985.

Baumgart EV, Barbosa JS, Bally-Cuif L, Gotz M, Ninkovic J. 2012. Stab wound injury of the zebrafish telencephalon: a model for comparative analysis of reactive gliosis. Glia 60:343-357.

Beauquis J, Roig P, Homo-Delarche F, De Nicola A, Saravia F. 2006. Reduced hippocampal neurogenesis and number of hilar neurones in streptozotocin-induced diabetic mice: reversion by antidepressant treatment. Eur J Neurosci 23:1539-1546.

Borsini A, Zunszain PA, Thuret S, Pariante CM. 2015. The role of inflammatory cytokines as key modulators of neurogenesis. Trends Neurosci 38:145-157.

Brismar T, Maurex L, Cooray G, Juntti-Berggren L, Lindstrom P, Ekberg K, Adner N, Andersson S. 2007. Predictors of 
cognitive impairment in type 1 diabetes. Psychoneuroendocrinology 32:1041-1051.

Capes SE, Hunt D, Malmberg K, Pathak P, Gerstein HC. 2001. Stress hyperglycemia and prognosis of stroke in nondiabetic and diabetic patients: a systematic overview. Stroke 32:2426-2432.

Capiotti KM, Antonioli R Jr, Kist LW, Bogo MR, Bonan CD, Da Silva RS. 2014a. Persistent impaired glucose metabolism in a zebrafish hyperglycemia model. Comp Biochem Phys B Biochem Mol Biol 171:58-65.

Capiotti KM, De Moraes DA, Menezes FP, Kist LW, Bogo MR, Da Silva RS. 2014b. Hyperglycemia induces memory impairment linked to increased acetylcholinesterase activity in zebrafish (Danio rerio). Behav Brain Res 274:319-325.

Chao AC, Lee TC, Juo SH, Yang DI. 2016. Hyperglycemia increases the production of amyloid beta-peptide leading to decreased endothelial tight junction. CNS Neurosci Ther 22:291-297.

Chapouton P, Jagasia R, Bally-Cuif L. 2007. Adult neurogenesis in non-mammalian vertebrates. BioEssays 29:745-757.

Chavin W, Young JE. 1970. Factors in the determination of normal serum glucose levels of goldfish, Carassius auratus L. Comp Biochem Physiol 33:629-653.

Chehade JM, Haas MJ, Mooradian AD. 2002. Diabetes-related changes in rat cerebral occludin and zonula occludens- 1 (ZO-1) expression. Neurochem Res 27:249-252.

Chen Y, Fan JX, Zhang ZL, Wang G, Cheng X, Chuai M, Lee KK, Yang X. 2013. The negative influence of high-glucose ambience on neurogenesis in developing quail embryos. PloS One 8:e66646.

Cherian L, Goodman JC, Robertson CS. 1997. Hyperglycemia increases brain injury caused by secondary ischemia after cortical impact injury in rats. Crit Care Med 25: 1378-1383.

Connaughton VP, Baker C, Fonde L, Gerardi E, Slack C. 2016. Alternate immersion in an external glucose solution differentially affects blood sugar values in older versus younger zebrafish adults. Zebrafish 13:87-94.

Cukierman T, Gerstein HC, Williamson JD. 2005. Cognitive decline and dementia in diabetes-systematic overview of prospective observational studies. Diabetologia 48:24602469.

Dejgaard A, Gade A, Larsson H, Balle V, Parving A, Parving HH. 1991. Evidence for diabetic encephalopathy. Diabet Med 8:162-167.

Desilles JP, Meseguer E, Labreuche J, Lapergue B, Sirimarco G, Gonzalez-Valcarcel J, Lavallee P, Cabrejo L, Guidoux C, Klein I, Amarenco P, Mazighi M. 2013. Diabetes mellitus, admission glucose, and outcomes after stroke thrombolysis: a registry and systematic review. Stroke 44:1915-1923.

Diotel N, Le Page Y, Mouriec K, Tong SK, Pellegrini E, Vaillant C, Anglade I, Brion F, Pakdel F, Chung BC, Kah $\mathrm{O}$. 2010a. Aromatase in the brain of teleost fish: expression, regulation and putative functions. Front Neuroendocrinol 31:172-192.

Diotel N, Vaillant C, Gueguen MM, Mironov S, Anglade I, Servili A, Pellegrini E, Kah O. 2010b. Cxcr4 and Cxcl12 expression in radial glial cells of the brain of adult zebrafish. J Comp Neurol 518:4855-4876.

Diotel N, Vaillant C, Gabbero C, Mironov S, Fostier A, Gueguen MM, Anglade I, Kah O, Pellegrini E. 2013. Effects of estradiol in adult neurogenesis and brain repair in zebrafish. Horm Behav 63:193-207.

Diotel N, Vaillant C, Kah O, Pellegrini E. 2016. Mapping of brain lipid binding protein (Blbp) in the brain of adult zebrafish, co-expression with aromatase B and links with proliferation. Gene Expr Patterns 20:42-54.
Eames SC, Philipson LH, Prince VE, Kinkel MD. 2010. Blood sugar measurement in zebrafish reveals dynamics of glucose homeostasis. Zebrafish 7:205-213.

Ergul A, Li W, Elgebaly MM, Bruno A, Fagan SC. 2009. Hyperglycemia, diabetes and stroke: focus on the cerebrovasculature. Vasc Pharmacol 51:44-49.

Esposito K, Nappo F, Marfella R, Giugliano G, Giugliano F, Ciotola M, Quagliaro L, Ceriello A, Giugliano D. 2002. Inflammatory cytokine concentrations are acutely increased by hyperglycemia in humans: role of oxidative stress. Circulation 106:2067-2072.

Fuster-Matanzo A, Llorens-Martin M, Hernandez F, Avila J. 2013. Role of neuroinflammation in adult neurogenesis and Alzheimer disease: therapeutic approaches. Mediators Inflamm 2013:260925.

Gaudieri PA, Chen R, Greer TF, Holmes CS. 2008. Cognitive function in children with type 1 diabetes: a meta-analysis. Diabetes Care 31:1892-1897.

Gilmore RM, Stead LG. 2006. The role of hyperglycemia in acute ischemic stroke. Neurocrit Care 5:153-158.

Grandel H, Brand M. 2013. Comparative aspects of adult neural stem cell activity in vertebrates. Dev Genes Evol 223: 131-147.

Gyurko R, Siqueira CC, Caldon N, Gao L, Kantarci A, Van Dyke TE. 2006. Chronic hyperglycemia predisposes to exaggerated inflammatory response and leukocyte dysfunction in Akita mice. J Immunol 177:7250-7256.

Hafez S, Coucha M, Bruno A, Fagan SC, Ergul A. 2014. Hyperglycemia, acute ischemic stroke, and thrombolytic therapy. Transl Stroke Res 5:442-453.

Hawkins BT, Lundeen TF, Norwood KM, Brooks HL, Egleton RD. 2007. Increased blood-brain barrier permeability and altered tight junctions in experimental diabetes in the rat: contribution of hyperglycaemia and matrix metalloproteinases. Diabetologia 50:202-211.

Ho N, Sommers MS, Lucki I. 2013. Effects of diabetes on hippocampal neurogenesis: links to cognition and depression. Neurosci Biobehav Rev 37:1346-1362.

Hsieh J. 2012. Orchestrating transcriptional control of adult neurogenesis. Genes Dev 26:1010-1021.

Huang J, Liu B, Yang C, Chen H, Eunice D, Yuan Z. 2013. Acute hyperglycemia worsens ischemic stroke-induced brain damage via high mobility group box-1 in rats. Brain Res 1535:148-155.

IDF. 2015. International Diabetes Federation. http://wwwidforg/.

Jakubs K, Bonde S, losif RE, Ekdahl CT, Kokaia Z, Kokaia M, Lindvall O. 2008. Inflammation regulates functional integration of neurons born in adult brain. J Neurosci 28: 12477-12488.

Jauch-Chara K, Oltmanns KM. 2014. Glycemic control after brain injury: boon and bane for the brain. Neuroscience 283:202-209.

Jung SH, Kim YS, Lee YR, Kim JS. 2016. High glucose-induced changes in hyaloid-retinal vessels during early ocular development of zebrafish: a short-term animal model of diabetic retinopathy. Br J Pharmacol 173:15-26.

Kagansky N, Levy S, Knobler H. 2001. The role of hyperglycemia in acute stroke. Arch Neurol 58:1209-1212.

Kaslin J, Ganz J, Brand M. 2008. Proliferation, neurogenesis and regeneration in the non-mammalian vertebrate brain. Philos Trans R Soc Lond B Biol Sci 363:101-122.

Kayama Y, Raaz U, Jagger A, Adam M, Schellinger IN, Sakamoto M, Suzuki H, Toyama K, Spin JM, Tsao PS. 2015. Diabetic cardiovascular disease induced by oxidative stress. Int J Mol Sci 16:25234-25263.

Kizil C, Kaslin J, Kroehne V, Brand M. 2012. Adult neurogenesis and brain regeneration in zebrafish. Dev Neurobiol 72:429-461. 
Kodl CT, Seaquist ER. 2008. Cognitive dysfunction and diabetes mellitus. Endocr Rev 29:494-511.

Koh GC, Peacock SJ, van der Poll T, Wiersinga WJ. 2012. The impact of diabetes on the pathogenesis of sepsis. Eur Clin Microbiol Infect Dis 31:379-388.

Kroehne V, Freudenreich D, Hans S, Kaslin J, Brand M. 2011. Regeneration of the adult zebrafish brain from neurogenic radial glia-type progenitors. Development 138:48314841.

Lam CS, März M, Strähle U. 2009. gfap and nestin reporter lines reveal characteristics of neural progenitors in the adult zebrafish brain. Dev Dyn 238:475-486.

Lang BT, Yan Y, Dempsey RJ, Vemuganti R. 2009. Impaired neurogenesis in adult type-2 diabetic rats. Brain Res 1258:25-33.

Lee IM, Shiroma EJ, Lobelo F, Puska P, Blair SN, Katzmarzyk PT, Lancet Physical Activity Series Working G. 2012. Effect of physical inactivity on major non-communicable diseases worldwide: an analysis of burden of disease and life expectancy. Lancet 380:219-229.

Lee R, Wong TY, Sabanayagam C. 2015. Epidemiology of diabetic retinopathy, diabetic macular edema and related vision loss. Eye Vision 2:17.

Letra L, Santana I, Seica R. 2014. Obesity as a risk factor for Alzheimer's disease: the role of adipocytokines. Metab Brain Dis 29:563-568.

Lin $\mathrm{Y}$, Berg $\mathrm{AH}$, lyengar $\mathrm{P}$, Lam TK, Giacca $\mathrm{A}$, Combs TP, Rajala MW, Du X, Rollman B, Li W, Hawkins M, Barzilai N, Rhodes CJ, Fantus IG, Brownlee M, Scherer PE. 2005. The hyperglycemia-induced inflammatory response in adipocytes: the role of reactive oxygen species. J Biol Chem 280:4617-4626.

Lin R, Cai J, Nathan C, Wei X, Schleidt S, Rosenwasser R, lacovitti L. 2015. Neurogenesis is enhanced by stroke in multiple new stem cell niches along the ventricular system at sites of high BBB permeability. Neurobiol Dis 74:229-239.

Lindsey BW, Tropepe V. 2006. A comparative framework for understanding the biological principles of adult neurogenesis. Prog Neurobiol 80:281-307.

Lindsey BW, Darabie A, Tropepe V. 2012. The cellular composition of neurogenic periventricular zones in the adult zebrafish forebrain. J Comp Neurol 520:2275-2316.

Lioupis C. 2005. Effects of diabetes mellitus on wound healing: an update. J Wound Care 14:84-86.

Lu FP, Lin KP, Kuo HK. 2009. Diabetes and the risk of multisystem aging phenotypes: a systematic review and metaanalysis. PloS One 4:e4144.

März M, Chapouton P, Diotel N, Vaillant C, Hesl B, Takamiya M, Lam CS, Kah O, Bally-Cuif L, Strähle U. 2010. Heterogeneity in progenitor cell subtypes in the ventricular zone of the zebrafish adult telencephalon. Glia 58:870-888.

März M, Schmidt R, Rastegar S, Strähle U. 2011. Regenerative response following stab injury in the adult zebrafish telencephalon. Dev Dyn 240:2221-2231.

Migaud M, Batailler M, Segura S, Duittoz A, Franceschini I, Pillon D. 2010. Emerging new sites for adult neurogenesis in the mammalian brain: a comparative study between the hypothalamus and the classical neurogenic zones. Eur J Neurosci 32:2042-2052.

Mooradian AD. 1997a. Central nervous system complications of diabetes mellitus-a perspective from the blood-brain barrier. Brain Res Brain Res Rev 23:210-218.

Mooradian AD. 1997b. Pathophysiology of central nervous system complications in diabetes mellitus. Clin Neurosci 4:322-326.

Ojo O, Brooke J. 2015. Evaluating the association between diabetes, cognitive decline and dementia. Int J Environ Res Public Health 12:8281-8294.
Olsen AS, Sarras MP Jr, Intine RV. 2010. Limb regeneration is impaired in an adult zebrafish model of diabetes mellitus. Wound Repair Regen 18:532-542.

Parimisetty A, Dorsemans AC, Awada R, Ravanan P, Diotel N, Lefebvre d'Hellencourt C. 2016. Secret talk between adipose tissue and central nervous system via secreted factors-an emerging frontier in the neurodegenerative research. J Neuroinflamm 13:67.

Pellegrini E, Mouriec K, Anglade I, Menuet A, Le Page Y, Gueguen MM, Marmignon MH, Brion F, Pakdel F, Kah O. 2007. Identification of aromatase-positive radial glial cells as progenitor cells in the ventricular layer of the forebrain in zebrafish. J Comp Neurol 501:150-167.

Prasad S, Sajja RK, Naik P, Cucullo L. 2014. Diabetes mellitus and blood-brain barrier dysfunction: an overview. J Pharmacovigil 2:125.

Rafalski VA, Brunet A. 2011. Energy metabolism in adult neural stem cell fate. Prog Neurobiol 93:182-203.

Randelli E, Buonocore F, Scapigliati G. 2008. Cell markers and determinants in fish immunology. Fish Shellfish Immunol 25:326-340.

Rosenberg CS. 1990. Wound healing in the patient with diabetes mellitus. Nurs Clin N Am 25:247-261.

Sander D, Kearney MT. 2009. Reducing the risk of stroke in type 2 diabetes: pathophysiological and therapeutic perspectives. J Neurol 256:1603-1619.

Sarras MP, Intine RV. 2013. Use of zebrafish as a disease model provides a unique window for understanding the molecular basis of diabetic metabolic memory. Hong Kong: iConcept Press. p 2611-2619.

Schmidt R, Strähle U, Scholpp S. 2013. Neurogenesis in zebrafish - from embryo to adult. Neural Dev 8:3.

Scott JF, Robinson GM, French JM, O'Connell JE, Alberti KG, Gray CS. 1999. Prevalence of admission hyperglycaemia across clinical subtypes of acute stroke. Lancet 353:376-377.

Storey S, Von Ah D. 2012. Impact of malglycemia on clinical outcomes in hospitalized patients with cancer: a review of the literature. Oncol Nurs Forum 39:458-465.

Stranahan AM, Arumugam TV, Cutler RG, Lee K, Egan JM, Mattson MP. 2008. Diabetes impairs hippocampal function through glucocorticoid-mediated effects on new and mature neurons. Nat Neurosci 11:309-317.

Tangvarasittichai S. 2015. Oxidative stress, insulin resistance, dyslipidemia and type 2 diabetes mellitus. World J Diabetes 6:456-480.

Tobin MK, Bonds JA, Minshall RD, Pelligrino DA, Testai FD, Lazarov O. 2014. Neurogenesis and inflammation after ischemic stroke: what is known and where we go from here. J Cereb Blood Flow Metab 34:1573-1584.

Wang WT, Lee P, Yeh HW, Smirnova IV, Choi IY. 2012. Effects of acute and chronic hyperglycemia on the neurochemical profiles in the rat brain with streptozotocin-induced diabetes detected using in vivo (1)H MR spectroscopy at 9.4 T. J Neurochem 121:407-417.

Waseem NH, Lane DP. 1990. Monoclonal antibody analysis of the proliferating cell nuclear antigen (PCNA). Structural conservation and the detection of a nucleolar form. J Cell Sci 96(Pt 1):121-129.

Whitmer RA. 2007. Type 2 diabetes and risk of cognitive impairment and dementia. Curr Neurol Neurosci Rep 7: 373-380.

Wiltrout C, Lang B, Yan Y, Dempsey RJ, Vemuganti R. 2007. Repairing brain after stroke: a review on post-ischemic neurogenesis. Neurochem Int 50:1028-1041.

World Health Organisation W. 2015a. Diabetes. http:// wwwwhoint/mediacentre/factsheets/fs312/en/.

World Health Organisation W. 2015b. Obesity and overweight. http://wwwwhoint/mediacentre/factsheets/fs311/en/. 
Wullimann M, Rupp B, Reichert H, Eds. 1996. Neuroanatomy of the zebrafish brain: a topological atlas. Basel, Switzerland: Birhaüser. p 1-144.

Yi SS, Hwang IK, Yoo KY, Park OK, Yu J, Yan B, Kim IY, Kim YN, Pai T, Song W, Lee IS, Won MH, Seong JK, Yoon YS. 2009. Effects of treadmill exercise on cell proliferation and differentiation in the subgranular zone of the dentate gyrus in a rat model of type II diabetes. Neurochem Res 34:1039-1046.

Yoo DY, Yim HS, Jung HY, Nam SM, Kim JW, Choi JH, Seong JK, Yoon YS, Kim DW, Hwang IK. 2016. Chronic type 2 diabetes reduces the integrity of the blood-brain barrier by reducing tight junction proteins in the hippocampus. J Vet Med Sci [Epub ahead of print].

Zhao C, Deng W, Gage FH. 2008. Mechanisms and functional implications of adult neurogenesis. Cell 132: 645-660.

Ziegler AN, Levison SW, Wood TL. 2015. Insulin and IGF receptor signalling in neural-stem-cell homeostasis. Nat Rev Endocrinol 11:161-170.

Zupanc GK, Hinsch K, Gage FH. 2005. Proliferation, migration, neuronal differentiation, and long-term survival of new cells in the adult zebrafish brain. J Comp Neurol 488: 290-319. 